\title{
Influence of urban form on the performance of road pavement solar collector system: Symmetrical and asymmetrical heights
}

Diana S.N.M. Nasir*, Ben Richard Hughes, John Kaiser Calautit

The University of Sheffield, United Kingdom

2

3

\begin{abstract}
Recent works have highlighted the importance of mitigating the urban heat island effect using innovative technologies. Several studies have emphasised the capabilities of the road pavement solar collector system to dissipate high temperature from the pavement/road surfaces not only to expand its lifecycle but also to reduce the Urban Heat Island effect. This study builds on previous research combining an urban configuration and a road pavement solar collector system in Computational Fluid Dynamics in order to understand the complicated connection of the urban environment and the road pavement. This study investigates the impact of the urban form on the performance of the road pavement solar collector focusing on comparing symmetrical and asymmetrical height of the urban street canyon. A 3D de-coupled simulation approach was used to simulate a macro domain (urban environment) and micro domain, which consists of road pavement solar collector pipes. ANSYS Fluent 15.0 was employed with the solar load model, Discrete Ordinate radiation model and Reynold Averaged Navier Stokes with standard $k$-epsilon equation. The simulation was carried out based on the summer month of June in Milan urban centre, Italy. Results showed a significant variation in the temperature results of road surface in comparing the three configurations. It was also found that there was a significant reduction in the RPSC system performance when taller building row was behind the first approaching building row. The method presented in this research could be useful for studying the integration of RSPC in various urban forms.
\end{abstract}

\section{Keyword: Urban Heat Island, urban street canyon, building simulation, Computational} Fluid Dynamics, road solar collector, heat transfer 
Previous related works have emphasised on the significant reduction of wind velocity penetrating the urban street canyon, in particular, canyons oriented perpendicularly to the wind direction [1], causing the rise in the air temperature in between the two narrowed street walls. This urban geometrical configuration was highlighted for its contribution in the formation of the Urban Heat Island (UHI) effect particularly within tight urban planning (tall buildings alongside narrow streets) with less open spaces [2]. Generally; as reported in the review paper of [3], studies of UHI effect have included three observation methods:

(i) field measurements,

(ii) thermal remote sensing, and

(iii) small-scale modelling. Another common approach is 'simulation', which includes energy balance and numerical modelling. The study of [4] highlighted the complex interactions between urban elements and the regional climate which resulted in numerical simulations preferred as an ideal tool to conduct urban thermal related assessment in all scales.

In 2012, a simplified two-dimensional mathematical model was developed in order to simulate air based UHI effect on two urban configurations: surface with two building rows and a surface with nobuilding The study highlighted the relation of UHI existence with the canyon aspect ratio; based on building height, $\mathrm{H}$ against the width between the building facades, $\mathrm{W}$ [5]. This ratio was included for the assessment of various urban air temperature and climatic studies [6]. Several studies have utilised fixed aspect ratio for analysis [7] but investigation on asymmetrical aspect ratios were also carried out [8]. Simulation of an urban configuration requires high effort to match with the realistic urban environment due to asymmetrical height of the buildings. Several researchers suggested to simplify the geometry patterns particularly by standardising the height of all simulated buildings [9]. Study of [10] has simulated multiple canyon geometry for comparative analysis but still retained the canyon aspect ratio in one particular standard.

The dynamic effects of the combination of solar heating and ambient wind speed in an urban canyon were investigated by [7]. The work highlighted that poor ventilation was observed within street canyon area as compared to the outside. It was mentioned in the published work of [2] that ground heating was observed to have an influence on the wind speed and the temperature at lower levels but with higher temperature facades of buildings, the buoyancy effect had more significant impact on the canyon air patterns [9]. Furthermore, there was an evidence of heat accumulation alongside the leeward wall as compared to the windward wall due to incapability of the air to dissipate the excessive heat away from the wall [1]. It was mentioned by [3] that the surface temperatures of an urban scale 3D street canyon were in unevenly distributed caused by the surface interaction to store, absorb and release heat from the heat sources i.e. solar radiation and airflow from all axis. The thermal instability that was caused by canyon air circulations has largely influence the pollution dispersion within street 
heat transport within street areas. This was observed when the streets were positioned perpendicular to the predominant wind direction, which reduces the ventilation cooling effect and subsequently reduces the heat release from surfaces. Therefore, high urban surface temperatures were noticed within the areas with low-access to wind velocity. In the study of [11], findings suggested that ground surface temperature was more sensitive to the variation of street canyon aspect ratio $(\mathrm{H} / \mathrm{W})$ during the night time and vice-versa for the wall temperature. Although it was mentioned that the increase in the aspect ratio could reduce the penetration of direct solar radiation, it should also be noted that the wall temperature increases with the decreasing convective cooling. In the afternoon, average wall temperature was higher due to increasing ground surface. By increasing longwave radiation, the walls opposite to the isolated walls were found warmer than the shaded walls.

According to [12]; it is assumed that the flow field in the urban area modelling is generated mainly based on the atmospheric motions. Computational Fluid Dynamics (CFD) can be utilised to investigate the dynamics of heat environment to determine temperature distribution, UHI effect and measurements on other aspect for urban planning. The CFD software allows to simulate the model in full scale configuration (1:1) based on the actual urban measurements [13]. In addition, to model passive energy design to achieve optimal thermal comfort, numerical methods such as CFD was also mentioned to be acceptable for its use due to its capability to parameterise extensive boundary conditions [14]. Overall, it is agreed that CFD modelling can provide higher resolution results and has a lot potential for many thermal related studies [15].

Additional option in reducing computational uncertainty is by validating CFD analysis with experimental data which is highly important to satisfy the quality assurance of the conducted numerical analysis [4]. Overview of CFD validation studies were listed in [4] and it was highlighted that more validation was conducted for microscale non-specific urban setting rather than for real urban setting. In recent, a review by [16] on CFD development and application suggested that a number of published papers without validation has slightly increased. This suggested that in some research, accuracy is unnecessary for the main study objective. It was objected by [17] which highlighted that although CFD has the ability to predict the modification of urban air velocity for investigating air dispersion, testing and validation procedures are also required and are as important as the modelling setup. It should be noted that previous researches on urban modelling were carried out by multidisciplinary approaches i.e. flow patterns across buildings [18] but it is worth to mention that most of the street canyon domain model was carefully developed based on COST Action 732 Best Practice Guideline (BPG) for CFD Simulation of Flows in the Urban Environment [19]. 


\subsection{Previous work: Road pavement solar collector as urban heating mitigation technique} Mitigation technology such as hydronic road pavement solar collector (RPSC) system was earlier proposed to reduce the absorbed temperature of road surface by flowing medium, which allows heat to be transferred from surface to bottom layers until it reaches the water pipes. In 1990s, outdoor measurement analysis has found the potential of asphaltic and dark type of pavement to intensify the thermal impact of outdoor environment due to excessive heat absorption as compared to the other tested materials, see the published work of [20]. Two decades later, the concern was not only the heat absorption but also regarding the underestimation of heat convection coefficient used during testing which caused an overestimated surface temperature values i.e. wind speed and temperature [21]. the observation of [22] also found an extremely high surface temperature during summer days, heat dissipation technologies for asphalt pavements were proposed with purpose to reduce air and surface temperature effects within urban environment [23]. In 2010, Asphalt Solar Collector (ASC) system which allows heat dissipation from the road surface by using a cooling medium was proposed while the absorbed heat was utilised for urban energy harnessing [24]. Concrete Solar Collectors (CSC) was proposed and developed for material thermal enhancement [25]. In 2013, using multi-layered pavement with higher porosity was preferred against the use of water pipe network due to improve system thermal efficiency for renewable energy and UHI mitigation. The system seems promising with the presented prototype with 75.0-95.0 \% efficiency but it also experienced issues such as low flow rates in the heat transfer of water medium across the porous pavement layer [26].

In this study, other types of solar collector technology were also reviewed, expanding the knowledge of each of the system performance for urban application. In 2012, a review of Massive Solar-Thermal Collectors (MSTC) highlighted the application of MSTC in three categories: (i) detached MSTC application from building envelope i.e. pavement or prefabricated structures, (ii) partially integrated MSTC via glazed and unglazed panels; and (iii) building integrated MSTC via building facade [27]. It was mentioned that the application of heat pump to exchange thermal energy with the ground encourages to use renewable source of low-enthalpy geothermal energy for heating and cooling buildings [28]. In the study, grouting materials used for the sealer of the buried pipe were investigated for the system thermal conductivity; demonstrating that natural and recycled aggregates provided an ideal thermal optimisation. An investigation by [29] studied the mechanism of critical free-area ratio (CFR) and its influencing factors using a simplified theoretical model to describe the heat and mass transfer process on pavement. Numerical investigation of inlet-outlet temperatures from water-inglass evacuated tube solar collector has found the necessity to obtain an optimum inlet-outlet temperature difference for optimum performance in thermal gain as well as to achieve less percentage error in validating experimental setup [30]. In the study of [31], the system efficiency and deficiency of a solar water heating system with evacuated tube collector and active circulation were investigated; demonstrating the reduction in the system efficiency with the increase in the water temperatures. This 
study highlighted the importance of the annual based analysis in determining the feasibility of the system for hot water supply systems.

Apart from the evaluation of solar collector systems based on its design parameters, the study of [32] highlighted the importance of investigating the system performance based on a number of outdoor parameters i.e. solar irradiation, wind speed, air temperature. From the urban-rural comparative analysis, it was concluded that weather condition according to time and location and urban characteristics (built form, topology) had a significant influence on the system performance efficiency. In 2015, the published work of [33] carried out CFD modelling of integrating the RPSC system with simplified urban canyon (two building rows) and to be compared with the integrated system with flat surface (no building canyon), as an alternative of evaluating the system in a near-torealistic event of UHI effect. Results have highlighted a significant unevenness in the temperature of the canyon road surface as compared to the flat surface, thus has increased the performance of RPSC in term of potential temperature collection (PTC) and surface temperature reduction (STR). Further investigation was carried out on the optimisation of RPSC via four designated parameters (inlet water velocity, water temperature, pipe depth and pipe diameter) within the two scenarios. The remark of the study was on the comparative analysis of the RPSC performance for urban application and rural application using the best condition of the system in obtaining optimum PTC and STR and conversely for the worst condition of the system [34].

\subsection{Aim and objectives}

This study builds on previous researches of urban RSPC system [33] and investigates the potential impact of modifying the shape of buildings from symmetrical [9] to asymmetrical form on the RPSC. The relevant of this study is based on the complex urban environment that consists of various types of topology in regards of the form, height or layout. In the earlier investigation, the urban configuration used in this work consisted of two building rows with symmetrical height with one road in between and the length of the street canyon was designed to be perpendicular to the direction of the airflow. The current evaluation includes the comparison of the street canyon in symmetrical height to the street canyon in asymmetrical height in two types which consists of: (i) the approaching building row has higher height as compared to the second building row, and (ii) the approaching building row has lower height as compared to the second building row. Based on these comparisons, this study aims to estimate the PTC and STR in \% of the RPSC system for each of the configuration and discussion were made further to the previous designated works. Further explanation on the research method is detailed in Section 3.

\subsection{Methods: De-coupled computational modelling}


177 Continuing from the previous study [33], a de-coupled computational modelling was proposed to 178 evaluate and compare the effect of symmetrical street canyon height and two types of asymmetrical 179 street canyon heights on road pavement solar collector (RPSC) system which was embedded in 180 between two building rows. The de-coupled modelling approach means two separated domains were 181 combined after the simulation results of primary domain (macro) which represents an outdoor urban 182 environment above road surface were exported to the secondary domain (micro) which represents a simplified pipe embedment within road pavement layer. Figure 1 shows the study method chart of the proposed de-coupled CFD approach.

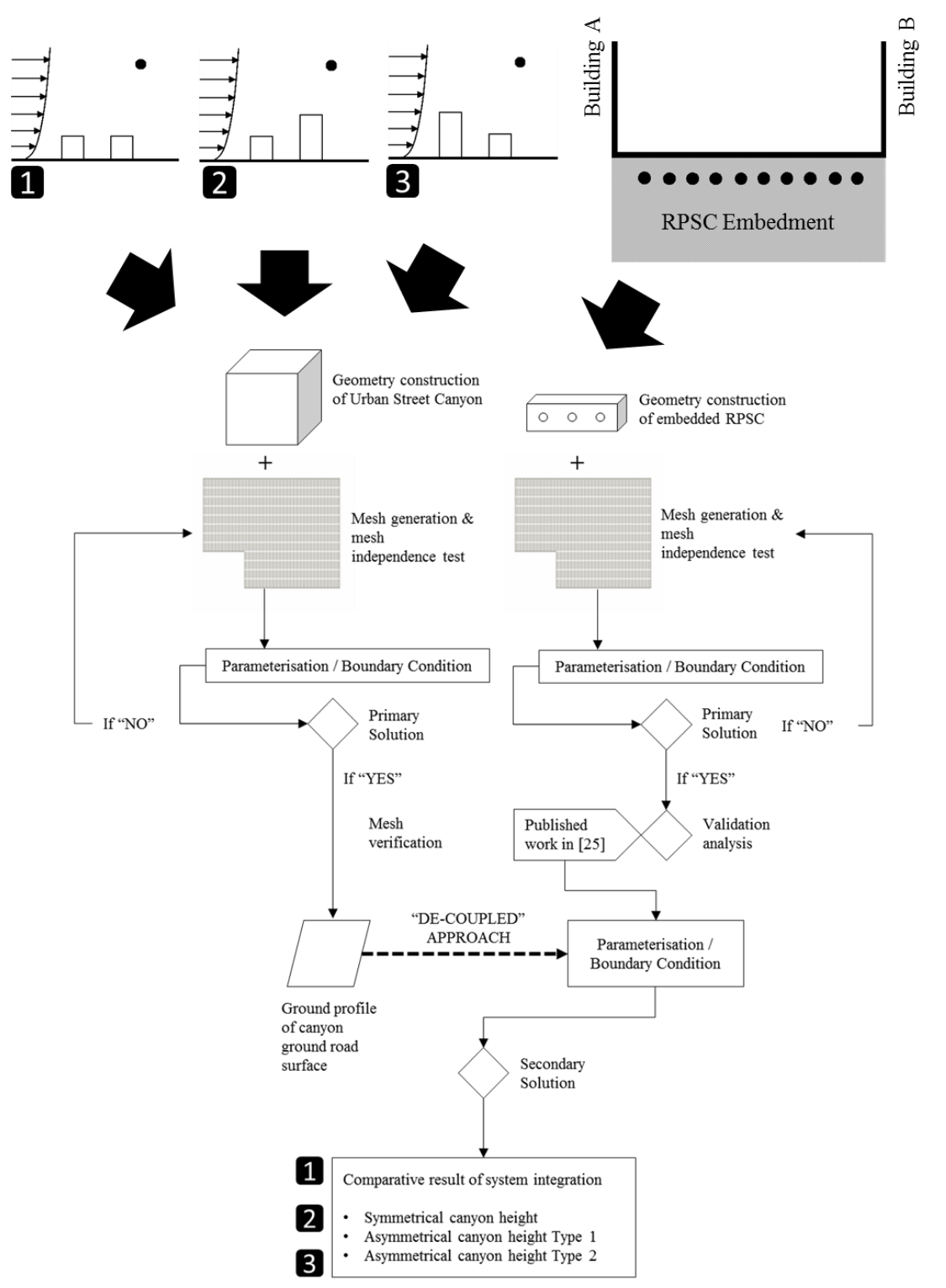

Figure 1: Method chart of de-coupled approach CFD model combining macro domain and micro domain

3.1 Macro domain: geometry and mesh description 
A fluid flow domain was built representing an urban environment above road surface with size 860.0 $\mathrm{m}$ length $\times 500.0 \mathrm{~m}$ width $\times 440.0 \mathrm{~m}$ total height in overall including two elongated building rows which were separated by $20.0 \mathrm{~m}$ width road surface in between. An inlet plane was determined to be $5 \mathrm{H}$ away from the first approaching building wall, to be named Windward Wall 1 of Building $\mathrm{A}$, meanwhile an outlet plane was determined to be $15 \mathrm{H}$ away from the second wall of the second building, to be named Leeward Wall 2 of Building B; see Figure 2.

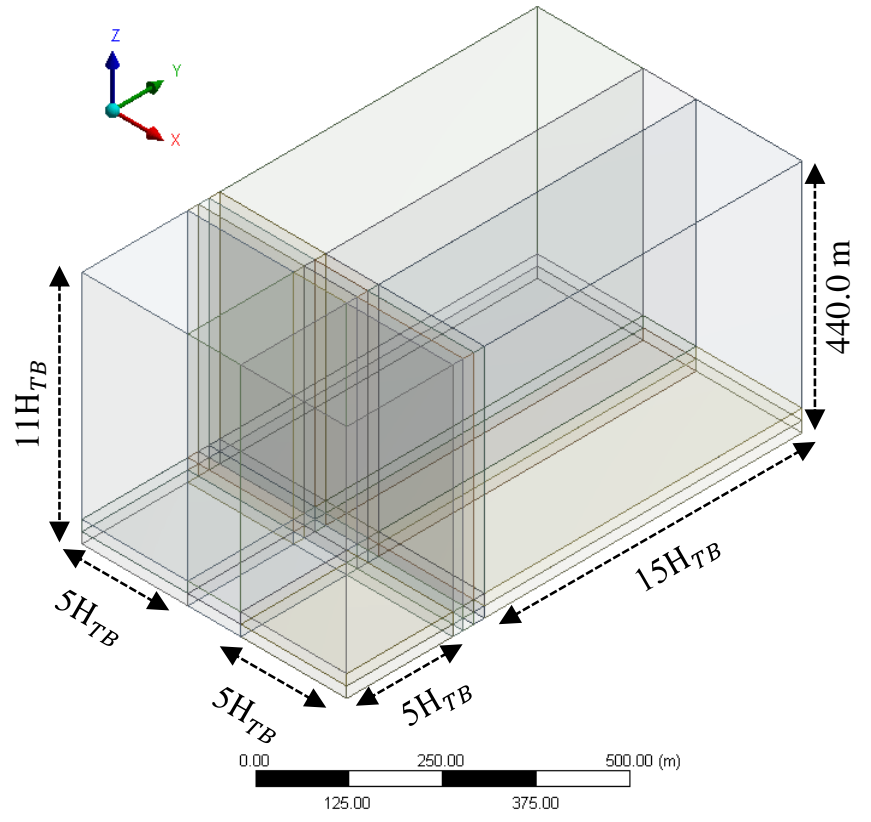

(a)

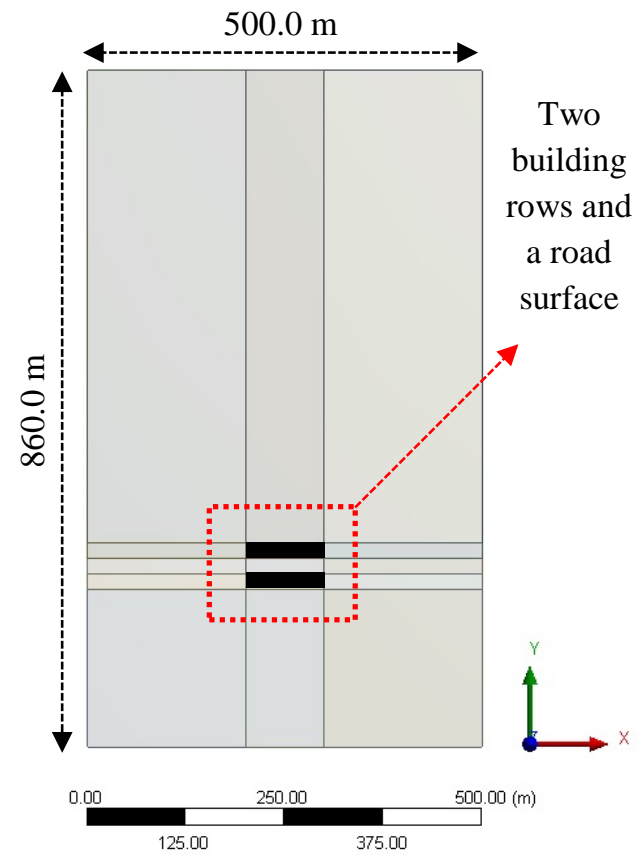

(b)

Figure 2: Geometry domain and description in (a) 3D perspective (b) top plan

The height of the fluid domain was determined as $11 \mathrm{H}$. The size of fluid flow has followed the recommendation of domain blockage ratio to be not more than $3.0 \%$ [19]. An elongated street canyon with two symmetrical building rows with the dimension $100.0 \mathrm{~m}$ length $\times 20.0 \mathrm{~m}$ width $\times 20.0 \mathrm{~m}$ height $(\mathrm{H})$ was compared to two types of asymmetrical elongated street canyons: (i) the first approaching building row has the height which was half the second approaching row (ii) the first approaching building row has the height which was double the second building row. This means the shortest building height, $\mathrm{H}_{S B}$ was set $20.0 \mathrm{~m}$ and the tallest building height, $\mathrm{H}_{T B}$ was set $40.0 \mathrm{~m}$. To standardise the size of the fluid flow domain for all three models, the reference height $(\mathrm{H})$ has to consider the tallest building height, $\mathrm{H}_{T B}$; thus $\mathrm{H}=\mathrm{H}_{T B}$. In addition, the analysis considered the building length of all domains to be perpendicular to the inlet airflow direction (in $y$ axis). The first approaching wall acted as an obstacle to the airflow which encourage the airflow turbulent development in the afterward until it reaches the outlet plane.

\subsubsection{Mesh setting}


211 Full structured mesh was set for overall macro domain emphasising finer grids at the area of interest;

212 building rows and street canyon surface. For the aforementioned setting; body slicing technique was

213 carried out, dividing the domain into 45 sub bodies including building volumes. Subsequently, all

214 body volumes were subtracted so that the interior of the buildings can be excluded from the boundary

215 condition. The first cell height in all sub-volumes can be set similar $0.25 \mathrm{~m}$ based on edge sizing;

216 generating more than 3 rows of cell above the first cell height before reaching $2.0 \mathrm{~m}$ pedestrian level

217 as recommended by [35]. Full application of edge sizing with hard behaviour and bias setting was

218 done on all sub bodies; see full description in Table 1 and generated mesh in three settings in Figure

219 3. Mesh verification was carried out comparing the macro domain with generated cells in coarse,

220 medium and fine setting.

Table 1: Mesh setting based on edge sizing

\begin{tabular}{|c|c|c|c|}
\hline Solution & Coarse mesh & Medium mesh & Fine mesh \\
\hline \multicolumn{4}{|l|}{ Edge sizing on macro domain } \\
\hline $\begin{array}{l}\text { Length between inlet and Windward Wall } 1 \\
\text { Building } \mathrm{A}\left(5 \mathrm{H}_{\mathrm{TB}}\right) \text { on } x \text { axis }(\mathrm{m})\end{array}$ & $\begin{array}{l}4.5 \text { with bias } \\
\text { factor } 10 \\
\end{array}$ & $\begin{array}{l}4.0 \text { with bias } \\
\text { factor } 10\end{array}$ & $\begin{array}{l}3.5 \text { with bias } \\
\text { factor } 10 \\
\end{array}$ \\
\hline $\begin{array}{l}\text { Length between inlet and Leeward Wall } 2 \\
\text { Building } \mathrm{B}\left(15 \mathrm{H}_{\mathrm{TB}}\right) \text { on } x \text { axis }(\mathrm{m})\end{array}$ & $\begin{array}{l}4.5 \text { with bias } \\
\text { factor } 10\end{array}$ & $\begin{array}{l}4.0 \text { with bias } \\
\text { factor } 10\end{array}$ & $\begin{array}{l}3.5 \text { with bias } \\
\text { factor } 10\end{array}$ \\
\hline $\begin{array}{l}\text { Width between symmetrical wall and building } \\
\text { edge walls }\left(5 \mathrm{H}_{\mathrm{TB}}\right) \text { on } y \text { axis }(\mathrm{m})\end{array}$ & $\begin{array}{l}4.5 \text { with bias } \\
\text { factor } 10\end{array}$ & $\begin{array}{l}4.0 \text { with bias } \\
\text { factor } 10\end{array}$ & $\begin{array}{l}3.5 \text { with bias } \\
\text { factor } 10\end{array}$ \\
\hline Up to $20.0 \mathrm{~m}$ above building height $\left(\mathrm{H}_{\mathrm{TB}}\right)(\mathrm{m})$ & $\begin{array}{l}4.5 \text { with bias } \\
\text { factor } 2\end{array}$ & $\begin{array}{l}4.0 \text { with bias } \\
\text { factor } 2\end{array}$ & $\begin{array}{l}3.5 \text { with bias } \\
\text { factor } 2\end{array}$ \\
\hline $\begin{array}{l}40.0 \mathrm{~m} \text { above ground level to symmetry } \\
\text { boundary wall }\left(10 \mathrm{H}_{\mathrm{TB}}\right)(\mathrm{m})\end{array}$ & $\begin{array}{l}13.0 \text { with bias } \\
\text { factor } 4\end{array}$ & $\begin{array}{l}12.0 \text { with bias } \\
\text { factor } 4\end{array}$ & $\begin{array}{l}10.0 \text { with bias } \\
\text { factor } 4\end{array}$ \\
\hline \multicolumn{4}{|l|}{ Edge sizing on building rows } \\
\hline Length on $x$ axis (m) & 1.15 & 1.0 & 0.85 \\
\hline Width on $y$ axis $(\mathrm{m})$ & 1.15 & 1.0 & 0.85 \\
\hline Building height $\left(\mathrm{H}_{\mathrm{TB}}\right)$ on $z$ axis $(\mathrm{m})$ & $\begin{array}{l}1.15 \text { with bias } \\
\text { factor } 10\end{array}$ & $\begin{array}{l}1.0 \text { with bias } \\
\text { factor } 10\end{array}$ & $\begin{array}{c}0.85 \text { with bias } \\
\text { factor } 10\end{array}$ \\
\hline \multicolumn{4}{|l|}{ Cell information } \\
\hline Total cell (nos) & $2,170,638$ & $2,988,000$ & $4,810,824$ \\
\hline Total node (nos) & $2,238,228$ & $3,072,420$ & $4,926,387$ \\
\hline
\end{tabular}
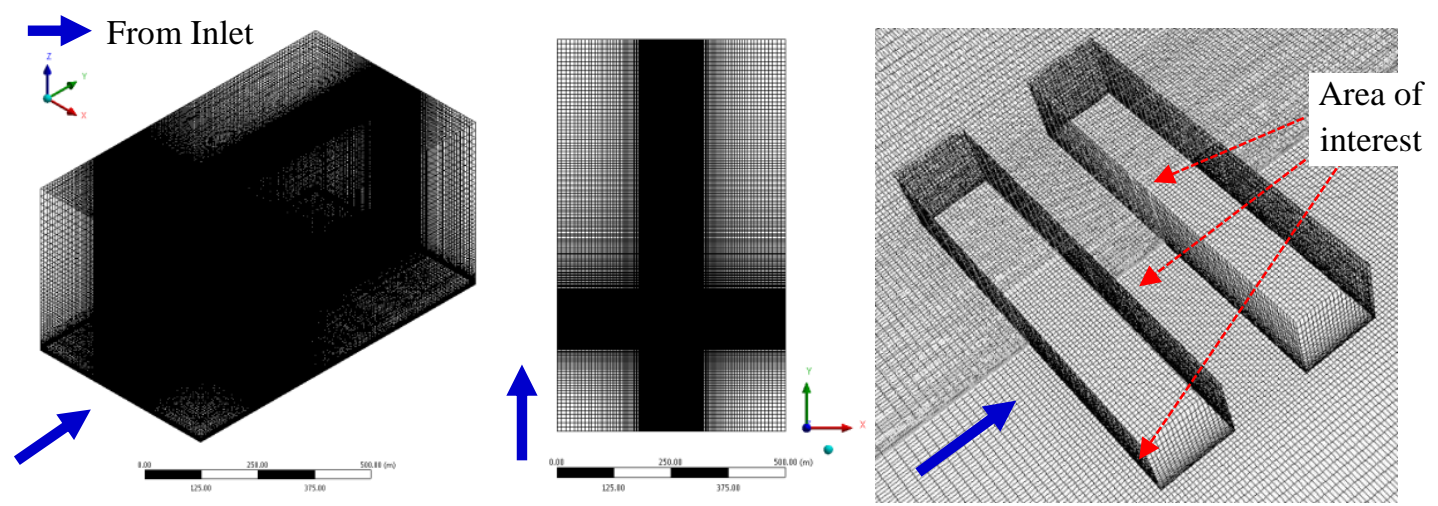

Figure 3: Full-structured mesh generated for macro domains comparing symmetrical and asymmetrical canyon height with cell refinement concentrated on area of interest

\subsubsection{Mesh verification}


227 To verify that the macro domain simulation was independent from the influence of grid sizing and cell 228 number, air pressure and air velocity magnitude were plotted in 11 points across the macro domain (in $229 y$ axis) above $60.0 \mathrm{~m}$ from the ground level $(0.0 \mathrm{~m})$ comparing coarse, medium and fine meshes. 230 Based on Figure 4(a), graph trend of all meshes were comparable except for nominal higher values plotted for 7 out of 11 points in fine mesh as compared to the other two meshes. In Figure 4(b), the graph trend can be mentioned comparable for all meshes between Location 1 (Loc1) to Location 6 (Loc6) as it was observed that the obtained gap was between $0.5-2.0 \mathrm{~m} / \mathrm{s}$ to compare the values afterward. However, velocity in all meshes seems decelerated when reaching outlet plane (Loc11).

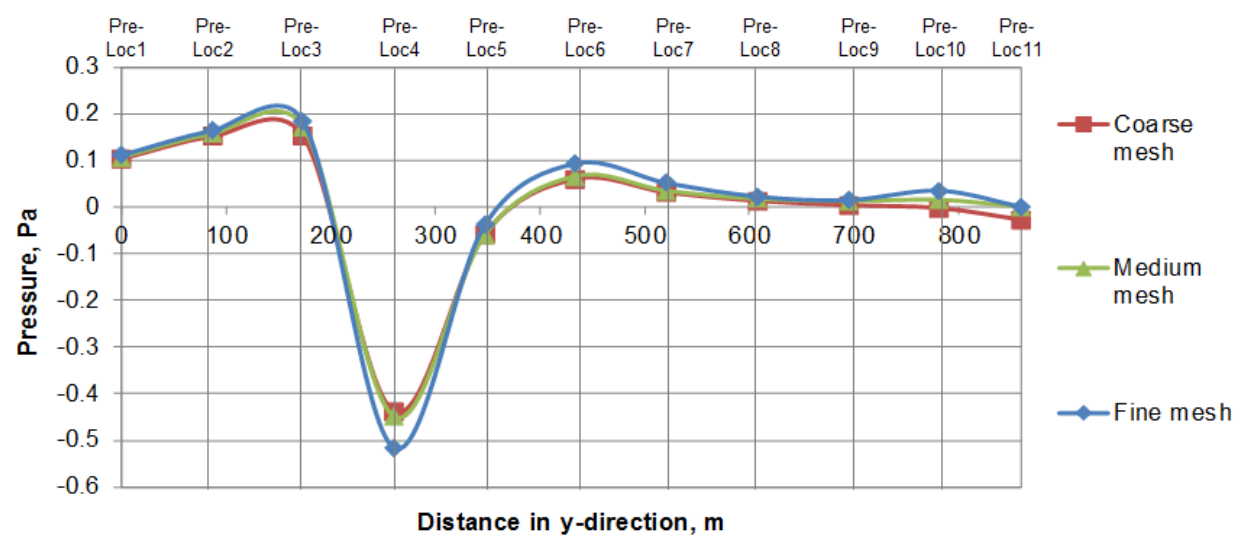

(a)

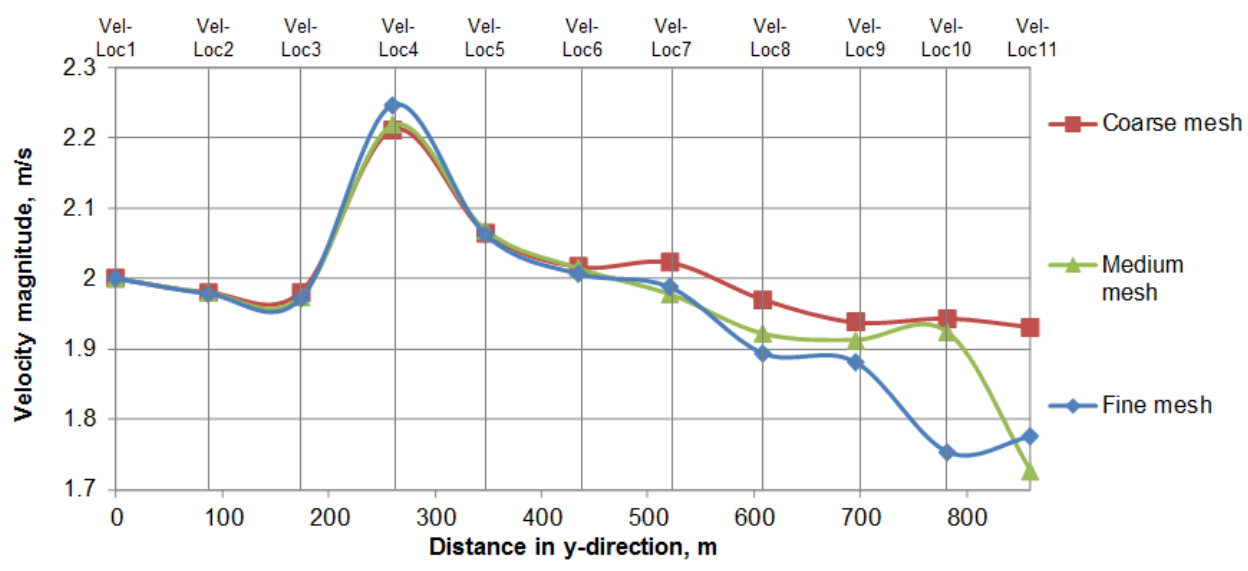

(b)

Based on the verification results, medium mesh was selected as the optimum mesh for the analysis as it shows comparable trend with the coarse mesh fine mesh while also reducing computational power requirement up to $40.0 \%$ as compared to fine mesh. 
It should be noted that based on the previous related work [33], RPSC system was layered underneath road surface within street canyon. In this study, RPSC pipes were assumed parallel to the length of the building rows approximately within the $10.0 \%$ area of the total ground road surface for simplification. 4 nos $20 \mathrm{~mm}$ diameter RPSC pipes were designed to be embedded $0.15 \mathrm{~m}(150 \mathrm{~mm})$ underneath road surface with the dimension $10.0 \mathrm{~m}$ length, $\mathrm{L} \times 1.0 \mathrm{~m}$ width, $\mathrm{W} \times 0.3 \mathrm{~m}(300 \mathrm{~mm})$ depth, D; see Figure 5. The gap between the pipes was set $0.25 \mathrm{~m}(250 \mathrm{~mm})$. As referred to the previous setting [33], three pipes were selected based on (i) the centre location, C; (ii) the pipe which the surface received highest temperature, A-5; and (iii) the pipe which the surface received lowest temperature, B-5. For simplifying the simulation, surface temperature within the area of $10.0 \mathrm{~m} \times 1.0$ $\mathrm{m}$ from the macro domain at the three aforementioned locations was exported for the boundary condition of the micro domain.

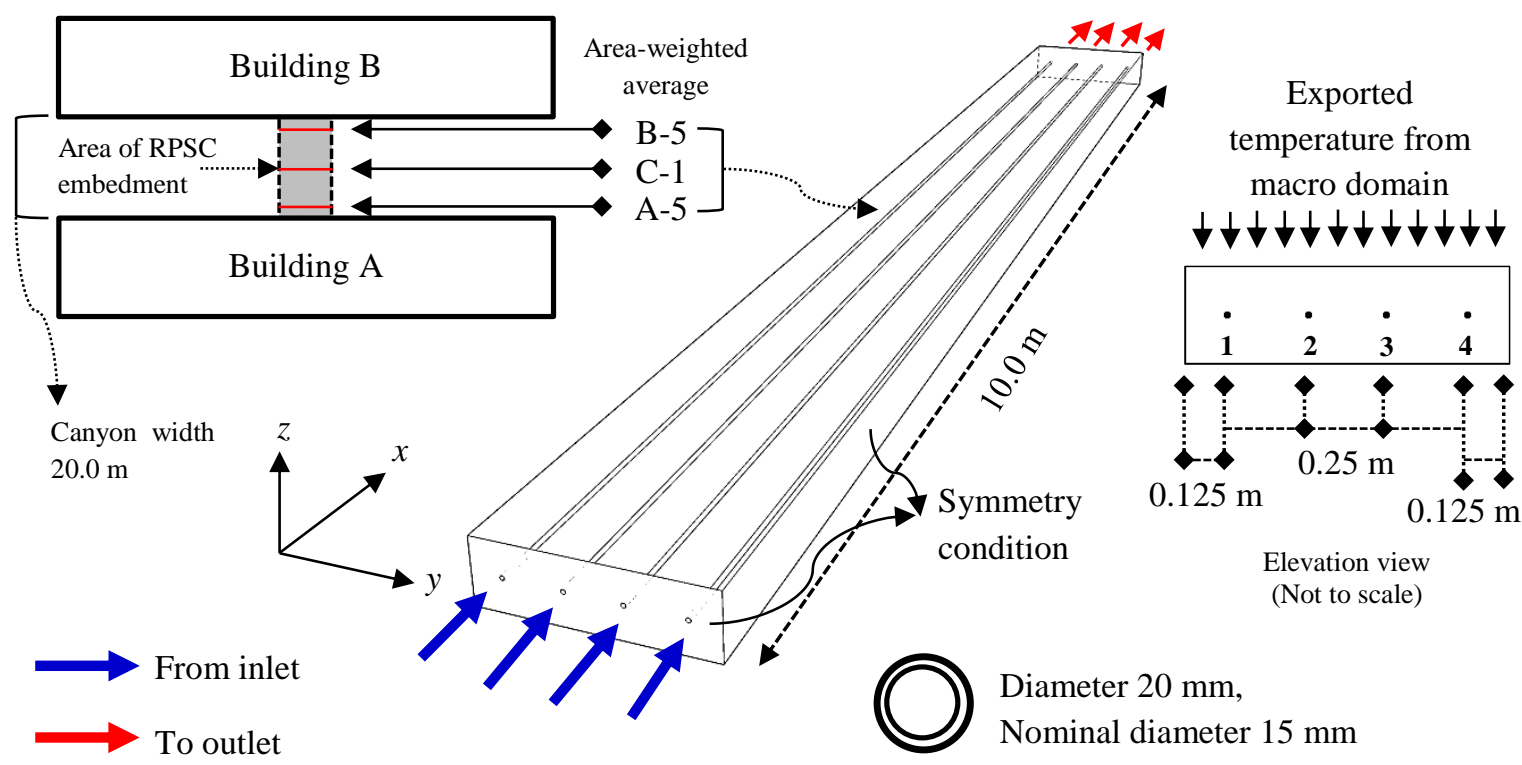

Figure 5: Configuration of micro domain (RPSC system) consisting 4 nos straight pipe

\subsubsection{Mesh setting}

Automated mesh was generated by sizing the edge of the pavement and pipe bodies; see Table 2 below. The micro domain was divided into 1 pavement body and 4 pipe bodies. For the pavement body; three sub bodies were created, separating the embedment region of the pipes from the upper layer and the lower layer. Hard behaviour on the edge sizing was set in order to force the generated cells of all pavement bodies in major hexahedral form so that full structured mesh can be obtained. Subsequently, this behaviour has to influence the cells generated for the pipe body; see Figure 6. 


\begin{tabular}{|c|c|c|c|}
\hline Solution & Coarse mesh & Medium mesh & Fine mesh \\
\hline \multicolumn{4}{|c|}{ Edge sizing on RPSC pavement and pipe bodies } \\
\hline Length on $x$ axis $(\mathrm{m})$ & 0.0250 & 0.02250 & 0.0200 \\
\hline Width on $y$ axis $(\mathrm{m})$ & 0.0010 & 0.00975 & 0.0095 \\
\hline Thickness on $Z$ axis (m) & 0.0010 & 0.00975 & 0.0095 \\
\hline Pipe length $(\mathrm{m})$ & 0.0250 & 0.02250 & 0.0200 \\
\hline \multicolumn{4}{|l|}{ Cell information } \\
\hline Total cell (nos) & $1,414,800$ & $1,625,140$ & $1,979,000$ \\
\hline Total node (nos) & $1,468,462$ & $1,687,664$ & $2,053,098$ \\
\hline
\end{tabular}

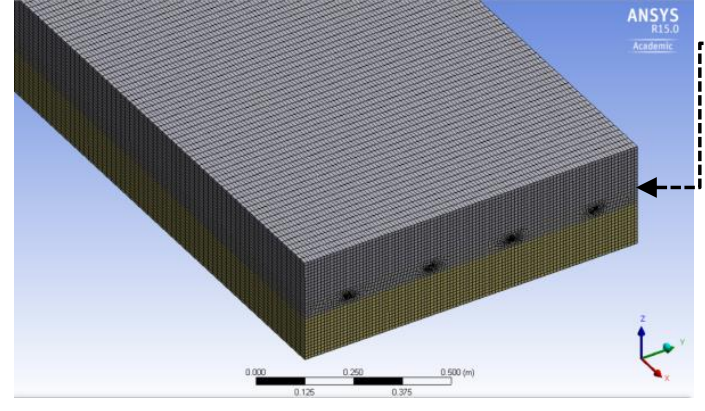

(a)

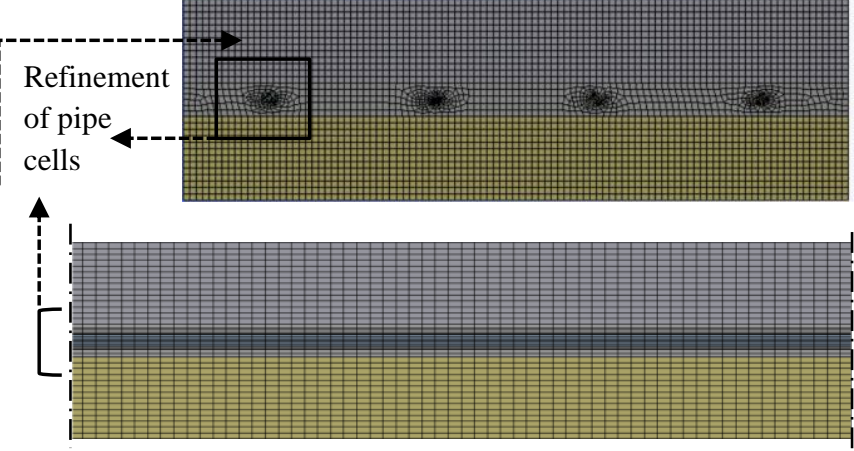

(b)
266

267

268

269

270

271

272

273

Figure 6: Example of generated medium mesh for micro domain

\subsubsection{Mesh validation of micro domain (RPSC pipes)}

The mesh settings (coarse, medium and fine) were validated against small-scale laboratory pavement with coil pipe [36] on temperature distribution plotted across pavement layers. The inlet flow rate for all meshes was set $1757 \mathrm{~mL} / \mathrm{min}(0.03 \mathrm{~kg} / \mathrm{s})$. As Figure 7, there were 15 points plotted across pavement depth, to be named Point 0 until Point 14. The pipe embedment for both setups (numerical and experimental) was located in the centre of pavement layer. In this study, the validation was carried out precisely at pipe 1 at the location $5.0 \mathrm{~m}$ away from the water inlet and $5.0 \mathrm{~m}$ away from the water outlet in $x$ axis. Only at seventh point, the plot was obtained outside the body of Pipe 1 following the published work of [36]; see Figure 7. Based on Figure 7, the error calculated for coarse mesh, medium mesh and fine mesh were on average $1.876 \%, 1.874 \%$ and $1.860 \%$ respectively. Out of 15 points, Point 3 for all three mesh settings had obtained the highest error value, not more than 5.0 $\%$. The comparison between the three mesh settings suggested that the obtained temperatures at all points were grid independent from the mesh cells with insignificant variance comparing the obtained values location to location. Thus, this study chose to carry out further investigations with fine mesh setting. 


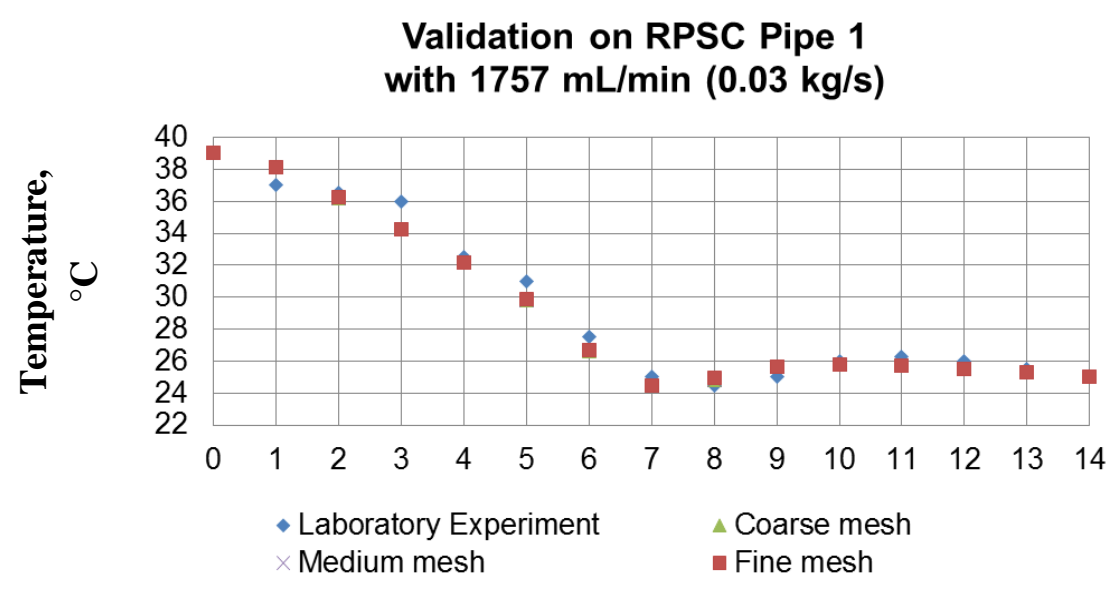

(a)

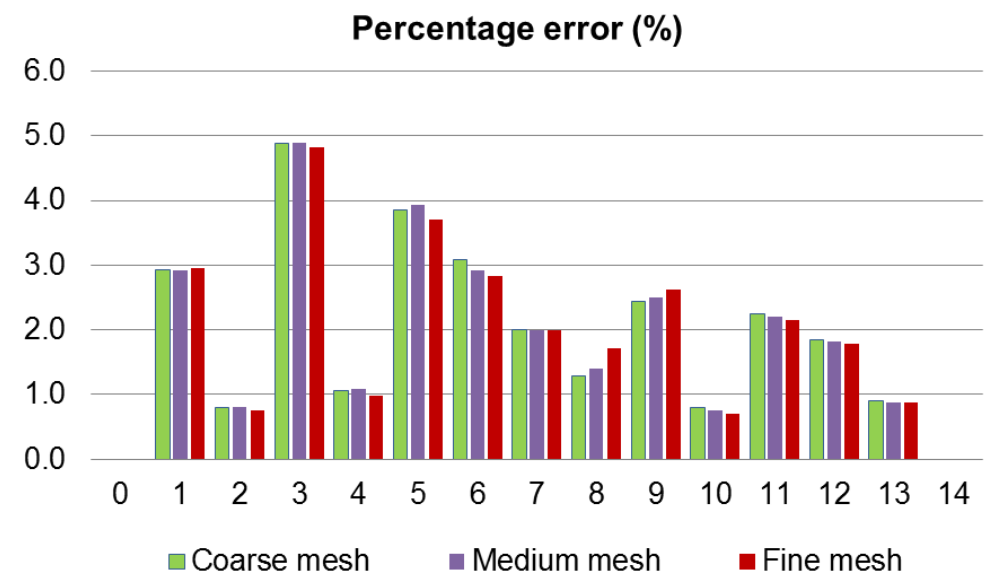

(b)

Figure 7: Verification of mesh and validation of temperatures across pavement layers (a) mesh against

laboratory results (b) percentage error, \%

\subsection{Boundary conditions}

287 For all macro domains, location of the simulation was set following the setting of [7] in Milan urban centre, Italy with longitude $9.18^{\circ} \mathrm{E}$, latitude $45.47^{\circ} \mathrm{N}$ and UTC +1 . The simulation took the consideration of a hot day with less wind [37] which was during summer $21^{\text {st }}$ June at 13:00 hour. The inlet air temperature was set $303 \mathrm{~K}\left(30^{\circ} \mathrm{C}\right)$ with a constant $2.0 \mathrm{~m} / \mathrm{s}$ air velocity. The turbulence intensity was set as $10.0 \%$ for assisting the turbulence development [9]. In this study, sand-grain roughness height $k_{s}$ was $0.25 \mathrm{~m}$ and roughness constant $\mathrm{C}_{\mathrm{s}}$ was set as default, 0.5. For RPSC pipes, $0.1 \mathrm{~m} / \mathrm{s}$ water velocity was set based on the lowest range of velocity input following [34] with turbulence intensity set as $0.08819 \%$ meanwhile the inlet water temperature was set as $293 \mathrm{~K}\left(20^{\circ} \mathrm{C}\right)$. Extending from the previous work [33], boundary conditions applied for wall surfaces are shown as Table 3. 
Table 3: Boundary condition applied to wall surfaces

\begin{tabular}{|c|c|c|c|c|c|c|c|}
\hline Description & $\begin{array}{l}\text { Surface } \\
\text { description }\end{array}$ & $\begin{array}{c}\text { Temperature } \\
\mathbf{K}\left({ }^{\circ} \mathrm{C}\right)\end{array}$ & $\begin{array}{c}\text { Thickness } \\
\text { (m) }\end{array}$ & $\begin{array}{l}\text { Density } \\
\left(\mathrm{kg} / \mathrm{m}^{3}\right)\end{array}$ & $\begin{array}{l}\text { Specific heat } \\
(\mathrm{J} / \mathrm{kg} \mathrm{K})\end{array}$ & $\begin{array}{c}\text { Thermal } \\
\text { conductivity } \\
(\mathrm{W} / \mathrm{m} \mathbf{K})\end{array}$ & Emissivity \\
\hline \multirow{2}{*}{$\begin{array}{l}\text { Validation } \\
\text { against } \\
\text { experiment work } \\
{[36]}\end{array}$} & $\begin{array}{l}\text { Pavement top } \\
\text { surface }\end{array}$ & $\begin{array}{c}312 \\
\left(39^{\circ} \mathrm{C}\right)\end{array}$ & NA & 1000 & 1000 & 0.9 & 0.9 \\
\hline & $\begin{array}{l}\text { Pavement } \\
\text { bottom } \\
\text { surface }\end{array}$ & $\begin{array}{c}298 \\
\left(25^{\circ} \mathrm{C}\right)\end{array}$ & NA & 1000 & 1000 & 0.9 & 0.9 \\
\hline $\begin{array}{l}\text { Macro domain } \\
\text { analysis } \\
\text { [7] }\end{array}$ & Pavement & 288 & NA & 1000 & 1000 & 0.9 & 0.9 \\
\hline \multirow{3}{*}{$\begin{array}{l}\text { Micro domain } \\
\text { analysis } \\
{[33]}\end{array}$} & Pavement & NA & NA & 1000 & 1000 & 0.9 & 0.9 \\
\hline & $\begin{array}{l}\text { Copper pipe } \\
\text { [38] }\end{array}$ & NA & $\begin{array}{l}0.005 \mathrm{~m} \\
(5 \mathrm{~mm})\end{array}$ & 8978 & 381 & 387.6 & 0.9 \\
\hline & $\begin{array}{l}\text { Water } \\
{[38]}\end{array}$ & $\begin{array}{c}293 \\
\left(20^{\circ} \mathrm{C}\right)\end{array}$ & NA & 998.2 & 4182 & 0.6 & NA \\
\hline
\end{tabular}

300

301

302

303

304

305

306

307

308

309

310

311

312

313

314

315

316

317

318

319

320

321

322

\subsection{Solution model}

For the simulation of three dimensional fluid flow and heat transfer within macro domain and between macro domain and micro domain, Finite Volume Method (FVM) combined with SIMPLE pressurebased solver in ANSYS Fluent 15.0 was selected. Effect of solar radiation on the area of interest requires using Solar Load model to load sunshine fraction on geometry based on locations (as mentioned in Section 3.3) coupled with Discrete Ordinate (DO) radiation model which treats all bodies as grey due to the emissivity of the materials. To simulate atmospheric boundary layer (ABL) in urban area; 3D pressure and steady Reynold Averaged Navier Stokes (RANS) with Standard $k$ epsilon $(k-\varepsilon)$ equation was used to solve turbulence development for high Reynold number [38]. This model was fully considered for its principle of momentum, continuity and heat conservation that used pressure and steady RANS equations meanwhile standard steady-state $k-\varepsilon$ model assumes an airflow is fully turbulent based on transport equation for turbulence kinetic energy $(k)$ and dissipation rate $(\varepsilon)$ [33].

\subsubsection{Performance calculation in temperature collection and surface temperature reduction}

In calculating the potential temperature collection (PTC) and surface temperature reduction (STR), pipe water inlet temperature $\left(T_{w, i}\right)$, water outlet temperature $\left(T_{w, o}\right)$, surface temperature before pipe simulation $\left(T_{s, \text { initial }}\right)$ and surface temperature after pipe simulation $\left(T_{s, \text { final }}\right)$ are required. In obtaining $T_{s, \text { final }}$, the surface static temperature on the mirror side of the surface that was imposed with initial measured temperature, $150 \mathrm{~mm}$ below the pipe location (centre-to-centre) was obtained. Calculation of Delta T, PTC and STR are explained as Equation 1, 2 and 3 below: 
325 Surface Temperature Reduction, STR (in $\left.{ }^{\circ} \mathrm{C}\right)=\left(T_{\text {s,initial }}-T_{\text {s, final }}\right) / T_{\text {s,initial }} \times 100.0 \%$

326

327

328

\subsection{Results and discussion}

This section discusses the results comparing the temperature distribution of the canyon surface between the three canyon settings (Section 4.1), sectional air velocity at the centre of the canyon (Section 4.2), temperature effect on the building facades for symmetrical and asymmetrical settings (Section 4.3) and analysis of RPSC performance based on PTC and STR in percentage (Section 4.4).

\subsection{Comparative analysis on temperature of canyon road surface}

Figure 8(a), 8(b) and 8(c) shows the surface temperature contour of elongated canyon road surface in symmetrical canyon height, asymmetrical canyon height Type 1 and asymmetrical canyon height Type 2; respectively. As the previous studies have highlighted regarding the orientation of solar radiation on domain [33], it should be noted that the Building B of these three cases was in the position which obstructed the nearby surfaces to obtain direct solar heat flux due to shadow effect and subsequently reduced the temperature of the nearby road surface. Previous studies have highlighted on the refraction of solar radiation towards the ground and facades of the Building A, caused temperature to elevate at the particular surfaces. With the modification of the canyon height, it was observed that its effect on surface temperature was significant. In Figure 8(a), lower surface temperature was observed near the right and left canyon openings on $x$ axis meanwhile higher temperature was observed at the centre of the canyon, confirming the previous analysis of [33]. 


\section{Temperature \\ Contour 1}

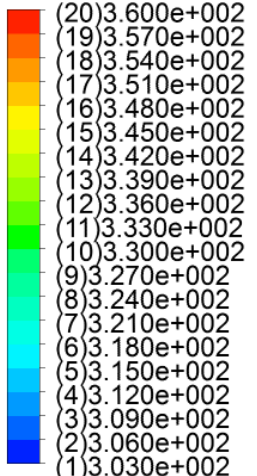

[K]

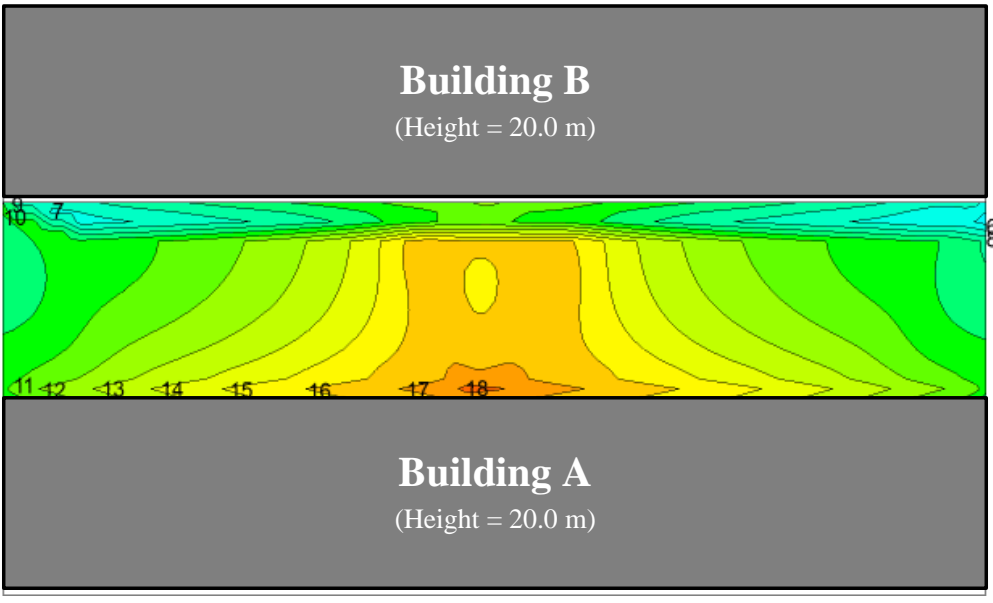

(a)

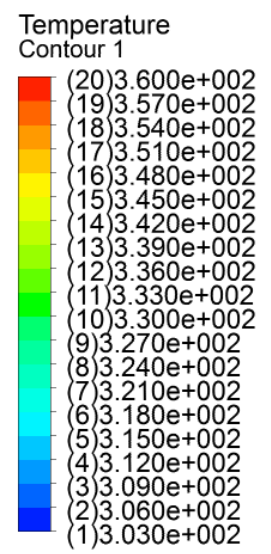

[K]

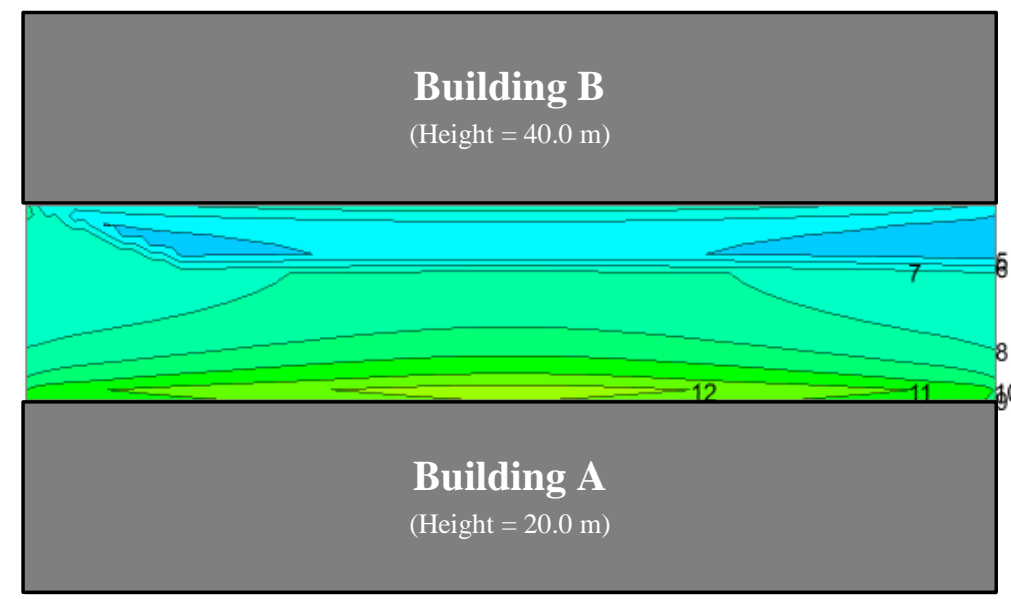

(b)
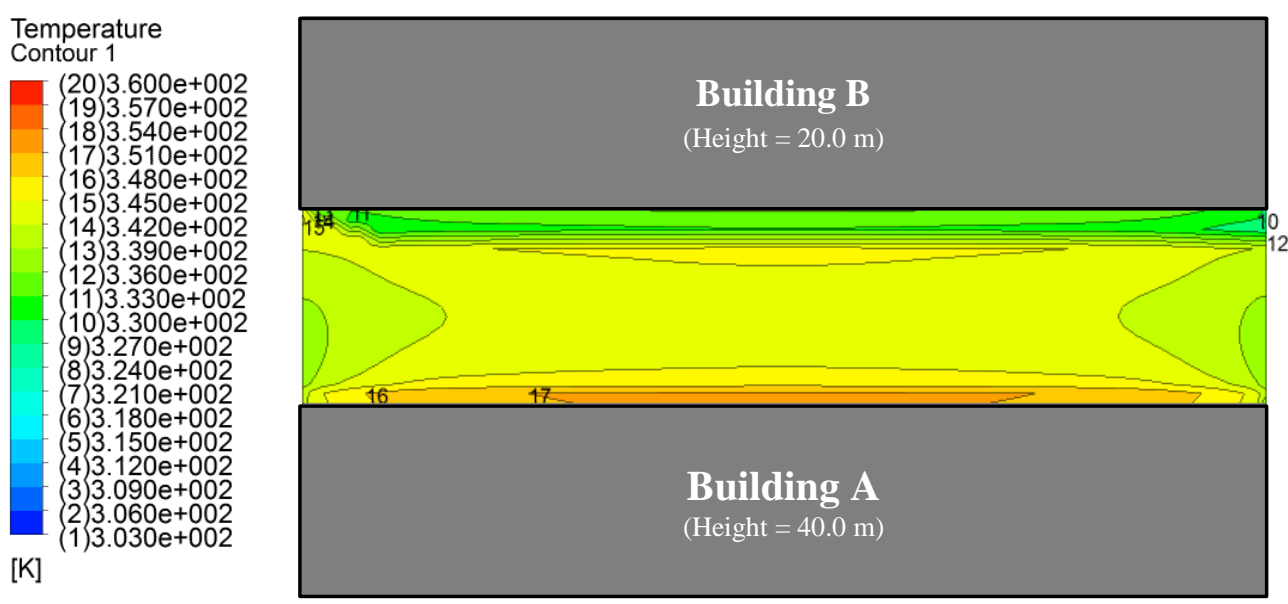

(c) 
Result based on asymmetrical canyon height Type 1 as per Figure 8(b) provided significant difference in trend. The Building B which was $20.0 \mathrm{~m}$ higher in height as compared to the Building A has caused larger shadowed area on canyon road surface with much lower temperature as compared to the result obtained with symmetrical canyon height. Refraction of solar radiation has occurred to the surface close by the Building A, conforming to the solution setting. Based on the analysis with asymmetrical canyon height Type 2 in Figure 8(c), it can be observed that the setting of lower building height on the second row has caused a similar shadow effect on canyon road surface as the symmetrical canyon height. However, the surface temperature at the centre towards right and left canyon openings was observed to be identical with fewer contours due to a better distribution of the temperature. Similar to the other canyon settings, the temperature of the canyon road surface close by the Building A obtained highest temperature over other surface area. Further discussion was carried out in Section 4.2 from the aspect of air velocity streamlines, which provided a clear explanation on the significant comparison in canyon surface temperature when street canyon height was modified.

\subsection{Comparative analysis on air velocity streamlines}

$3 \mathrm{D}$ air velocity streamlines were analysed with forward and backward effects in comparing the three aforementioned street canyon settings; see Figure 9. Overall, the first façade wall (Leeward Wall 1) has caused the airflow to cross over the street canyon and simultaneously to be dispersed to the canyon edges in avoiding the vertical obstacle. Penetration of air from the canyon openings was observed in all settings. However, with asymmetrical height, airflow movement was found to be significantly modified. Based on Figure 9(b); it can be observed that the obstruction from the Building $\mathrm{B}$ which has higher height has caused the swirling air directed down to the canyon road surface, cooling the temperature of the surface. Simultaneously, the shadow of the Building B has increased the cooling effect. With symmetrical canyon height setting as per Figure 9(a); swirling air was observed more visible at the right and left openings, creating uneven temperature distribution from low (closer the openings) to high (centre of street canyon). This effect was also combined with the refraction of solar radiation on the surface with less shadows resulted in higher overall temperature as compared to the asymmetrical canyon settings. Based on Figure 9(c), the obstructed Leeward Wall 1 of the Building A has caused larger swirling air passed over the Building B due to air movement based on high to low pressure. It should be noted that the penetration of air from the canyon openings (top, right and left) also occurred but with minimal effect on cooling the temperature of the canyon road surface. This can be observed from the surface temperature contour classified at (15) or $345.0 \mathrm{~K}$ has dominated approximately $60.0 \%$ of the total surface area. Correlation between the street canyon height and heat transfer from the solution model to the canyon road surface was further discussed in Section 4.3. In this section, 3D analysis of the temperature of building facades facing street canyon was carried out. 

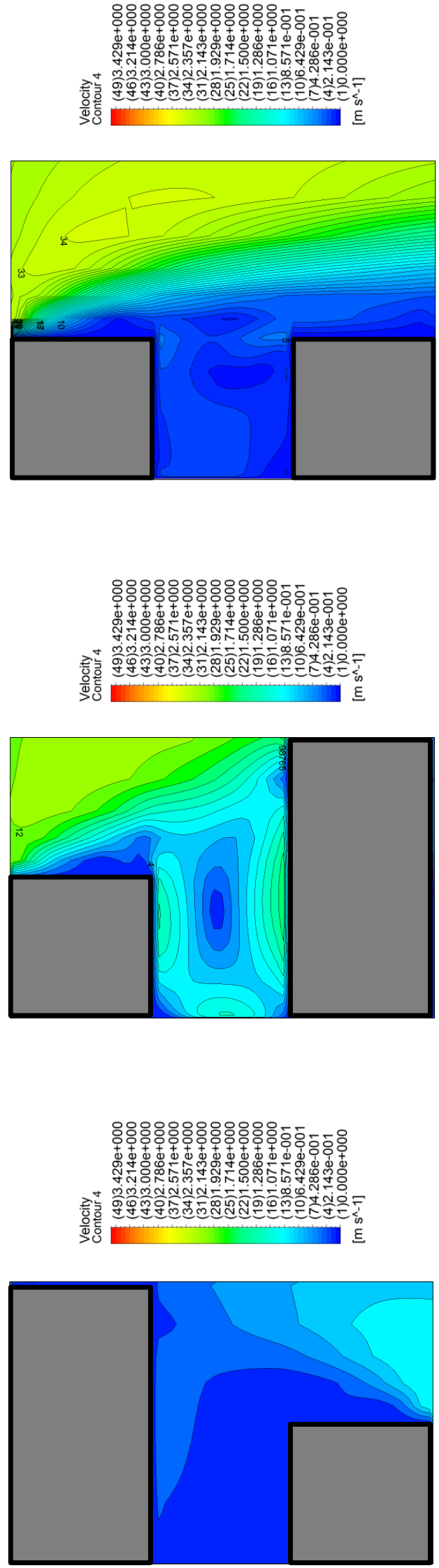

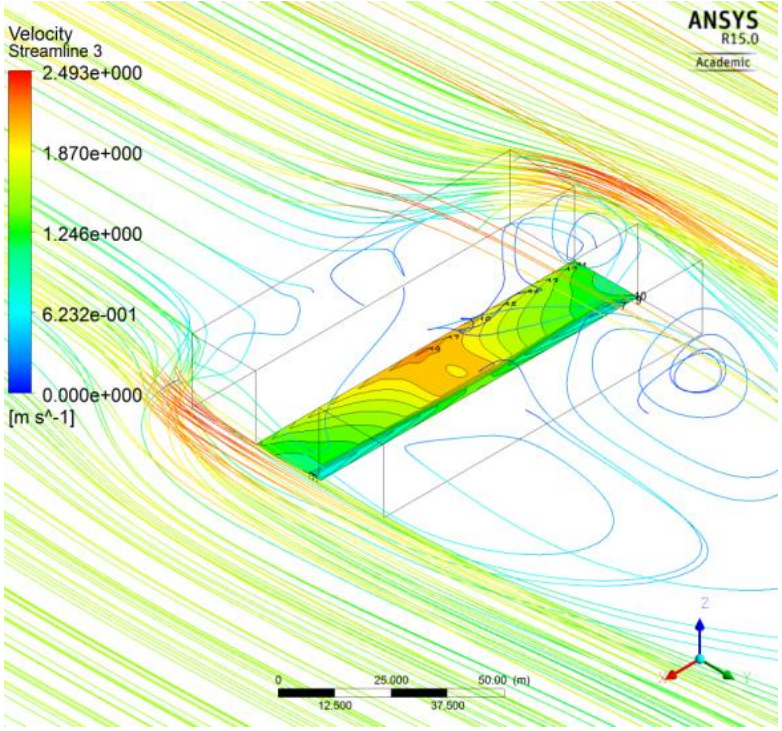

(a)

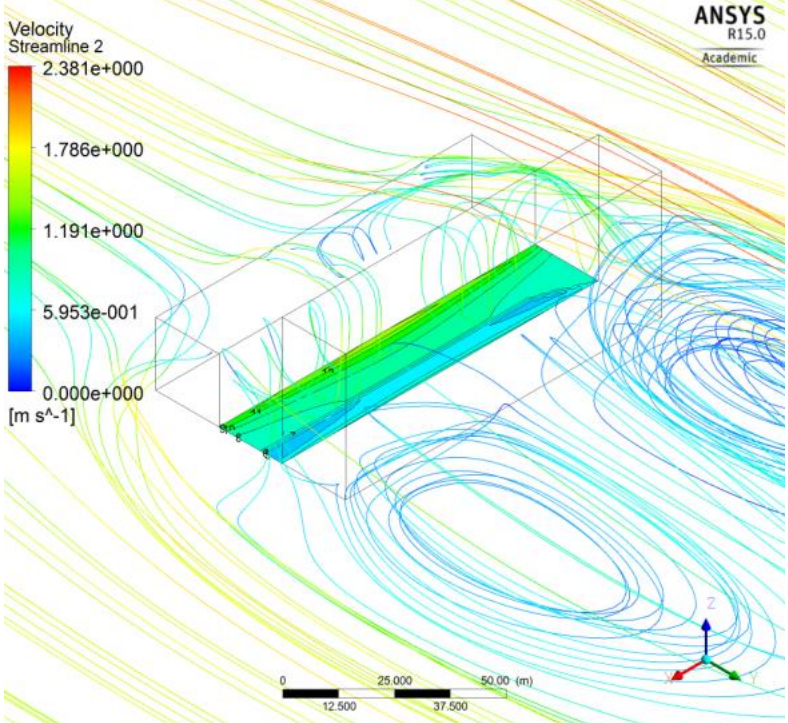

(b)

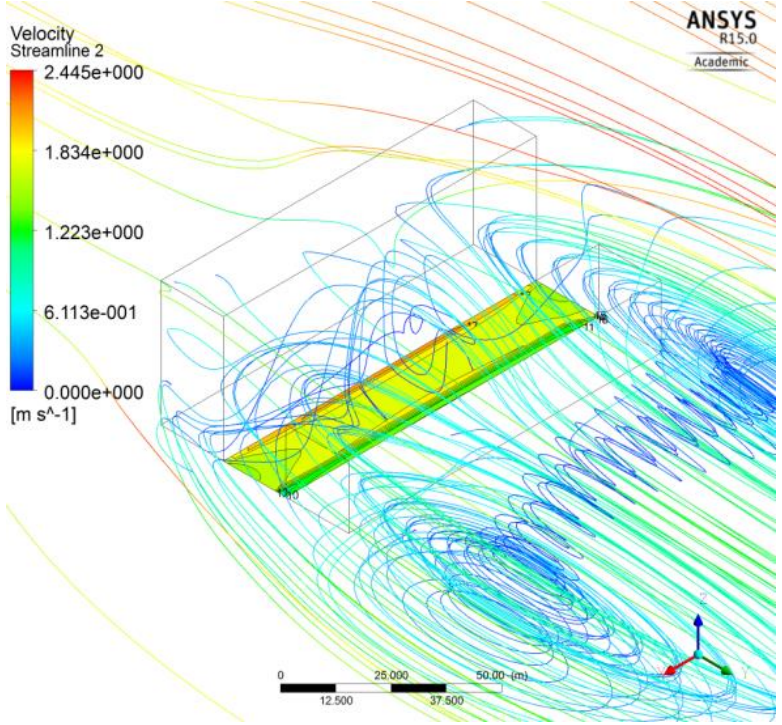

(c)

Figure 9: Air velocity streamlines comparing 
394 Figure 10 (a), 10(b) and 10(c) demonstrates the temperature contour of building facades facing street canyon (Leeward Wall 1 for Building A and Windward Wall 1 for Building B) for symmetrical canyon height, asymmetrical canyon height Type 1 and asymmetrical canyon height Type 2; respectively. As shown in Figure 10, the temperature contour of all façades facing street canyon has gradually increased according to the height. The closer to the ground, the higher the temperature was obtained, depending on the fraction of solar radiation and the temperature of canyon road surface. Based on Figure 10(a-i) and 10(a-ii), it can be observed that higher temperature contour was at the centre of the facades closer to the road level; similarly followed the trend of canyon road surface. For asymmetrical canyon height Type 1, the Windward Wall 2 (see Figure 10(b-i)) has double the façade area as compared to other street canyon settings. As the obstruction to the airflow occurred, the swirling air within the street canyon aided to reduce the temperature of the façade more than Windward Wall 2 of other street canyon settings. As for the Leeward Wall 1 (see Figure 10(b-ii)), the obstruction from the Building $\mathrm{B}$ in receiving direct solar radiation has shown that the façade has obtained almost identical low temperature except for nominal temperature difference nearby the canyon openings (right and left) and closer to the road level.

410 The temperature contour was observed to be in higher range (from ground level to rooftop level) with 411 almost identical temperature distribution from the right opening to the left opening for the Leeward 412 Wall 1 of asymmetrical canyon height Type 2; see Figure 10(c-i). Meanwhile for Windward Wall 2 as 413 per Figure 10(c-ii), almost $50.0 \%$ of the surface area nearby the road level was observed with the 414 temperature contour classified at 14 or with $342.0 \mathrm{~K}$. As mentioned in the previous section; the 415 increased height of the Building A over the Building B has caused large air swirl passed over the 416 Building $\mathrm{B}$, reducing the penetration of airflow from the right and left canyon openings. Thus, the temperature for Windward Wall 2 was observed to be almost identical end to end of the facades. 

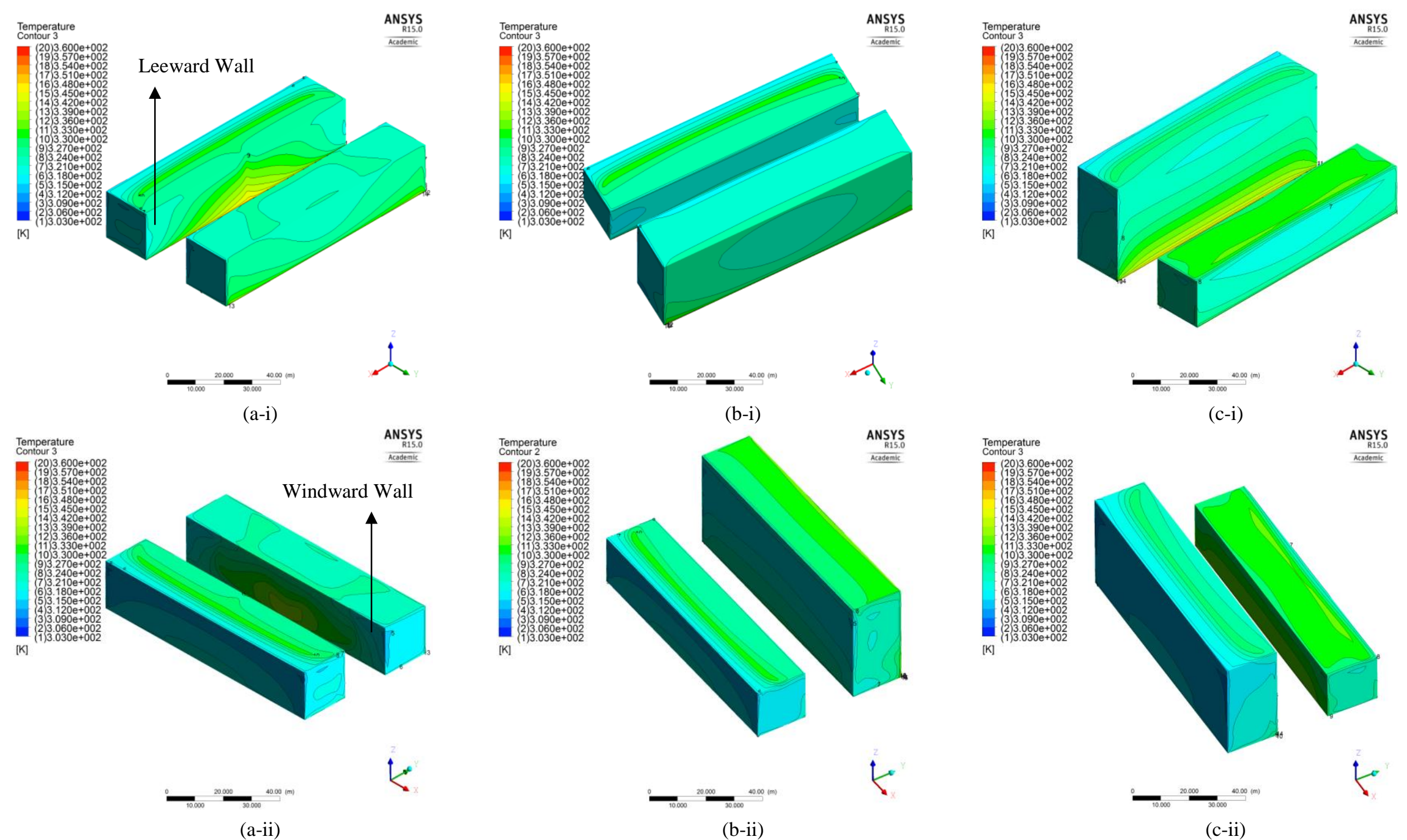

(b-i)
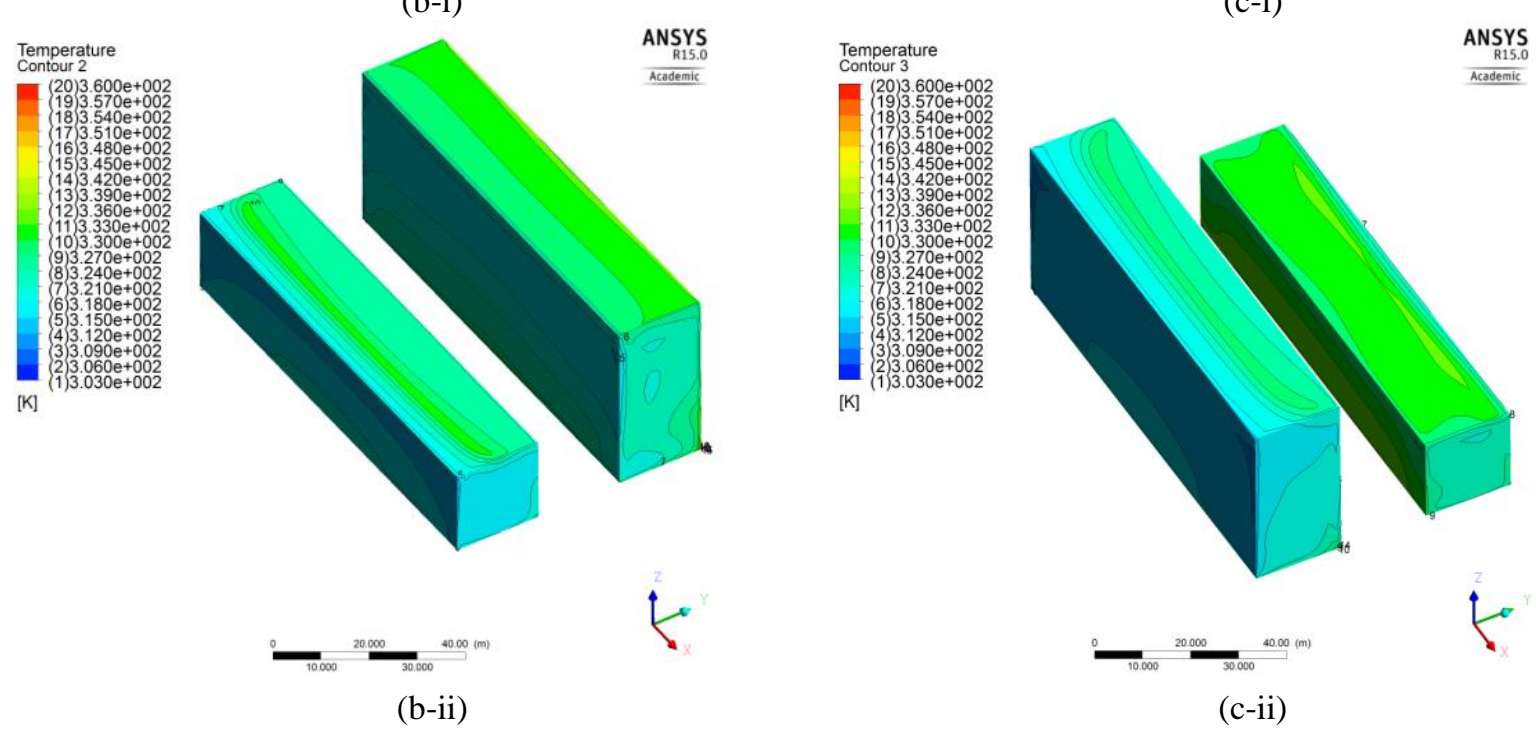

(a) Symmetrical canyon height $-i \& i i$ (b) Asymmetrical canyon height Type $1-i \& i i$ (c) Asymmetrical canyon height Type $2-i$ \& ii 


\subsection{RPSC performance based on macro domain}

421 This section discusses the results of the RPSC system simulation that utilised the values of average

422 surface temperature imported from the simulation of macro domain. As mentioned in Section 3.2,

423 three locations were selected based on: (i) the centre location, C; (ii) the surface that received highest

424 temperature, A-5; and (iii) the surface that received lowest temperature, B-5. Figure 11 demonstrates

425 the comparative results of 10 temperature points plotted from the canyon surface between the location

$426245 \mathrm{~m}$ and the location $255 \mathrm{~m}$ in $x$ axis. Based on the results; it was observed that the symmetrical

427 canyon height has caused canyon road surface to obtain higher temperature for location C and A-5 by

$428 \quad 25.21-43.93 \%$ and 3.15-6.51\% than the asymmetrical canyon height Type 1 and asymmetrical

429 canyon height Type 2, respectively. For location B-5, it was observed that the surface within the

430 asymmetrical canyon height Type 2 has obtained $0.31 \%$ surface temperature higher than the

431 symmetrical canyon height. Meanwhile, the surface within the asymmetrical canyon height Type 1

432 has obtained the lowest temperature; 20.14-23.08\% behind the other two canyon settings. Based on

433 the plotted points, an average temperature of $\boldsymbol{T}_{\boldsymbol{s} \text {,initial }}$ was calculated and to be set as the boundary

434 condition for the micro domain. The final temperature $\boldsymbol{T}_{\boldsymbol{s} \text {,final }}$ was then obtained to calculate STR in

$435 \%$; see Table 4.

436

437 Table 4: Calculation of average surface temperature according to locations

\begin{tabular}{|c|c|c|c|c|c|c|c|c|c|}
\hline \multirow{2}{*}{ Plot No } & \multicolumn{3}{|c|}{ Pipe B-5 } & \multicolumn{3}{|c|}{ Pipe C-1 } & \multicolumn{3}{|c|}{ Pipe A-5 } \\
\hline & SCH & AC1 & $\mathrm{AC2}$ & SCH & AC1 & AC2 & SCH & AC1 & $\mathrm{AC2}$ \\
\hline Point_1 & 333.32 & 319.88 & 333.84 & 349.39 & 344.04 & 344.04 & 353.02 & 337.36 & 351.32 \\
\hline Point_2 & 333.84 & 319.88 & 333.84 & 348.35 & 344.04 & 344.04 & 353.53 & 337.36 & 351.32 \\
\hline Point_3 & 334.36 & 319.88 & 334.33 & 347.83 & 344.04 & 344.04 & 354.57 & 337.36 & 351.32 \\
\hline Point_4 & 334.88 & 319.88 & 334.33 & 347.83 & 344.04 & 344.04 & 354.57 & 337.36 & 351.32 \\
\hline Point_5 & 334.87 & 319.88 & 334.33 & 347.83 & 344.04 & 344.04 & 354.57 & 337.77 & 351.32 \\
\hline Point_6 & 334.87 & 319.88 & 334.33 & 347.83 & 344.04 & 344.04 & 354.57 & 337.77 & 351.32 \\
\hline Point_7 & 333.84 & 319.88 & 334.33 & 348.35 & 344.04 & 344.04 & 354.05 & 337.77 & 351.32 \\
\hline Point_8 & 333.32 & 319.88 & 334.33 & 349.39 & 344.04 & 344.04 & 353.53 & 337.77 & 351.32 \\
\hline Point_9 & 333.32 & 319.88 & 333.84 & 349.91 & 344.04 & 344.04 & 353.02 & 337.36 & 351.32 \\
\hline Point_10 & 332.80 & 319.88 & 333.84 & 349.91 & 344.04 & 344.04 & 352.50 & 337.36 & 351.32 \\
\hline $\begin{array}{c}\text { Average } \\
T_{\text {s,initial }}, \mathbf{K}\end{array}$ & 333.94 & 319.88 & 334.13 & 348.66 & 344.04 & 344.04 & 353.79 & 337.52 & 351.32 \\
\hline $\begin{array}{c}\text { Average } \\
T_{\text {s,final }}, \mathbf{K}\end{array}$ & 308.18 & 302.97 & 308.25 & 313.64 & 305.08 & 311.93 & 315.55 & 309.51 & 314.63 \\
\hline
\end{tabular}

$\mathrm{SCH}=$ Symmetrical Canyon Height, AC1 = Asymmetrical Canyon Height Type 1, AC2 = Asymmetrical Canyon Height Type 2 


\section{Pipe C-1}

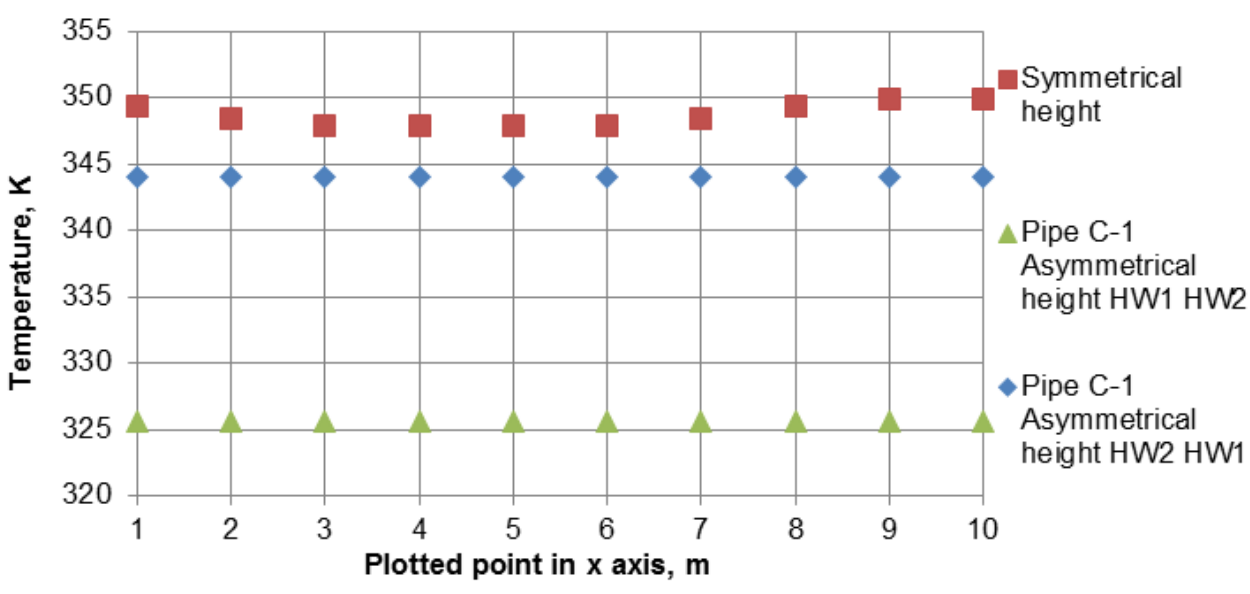

(a)

\section{Pipe A-5}

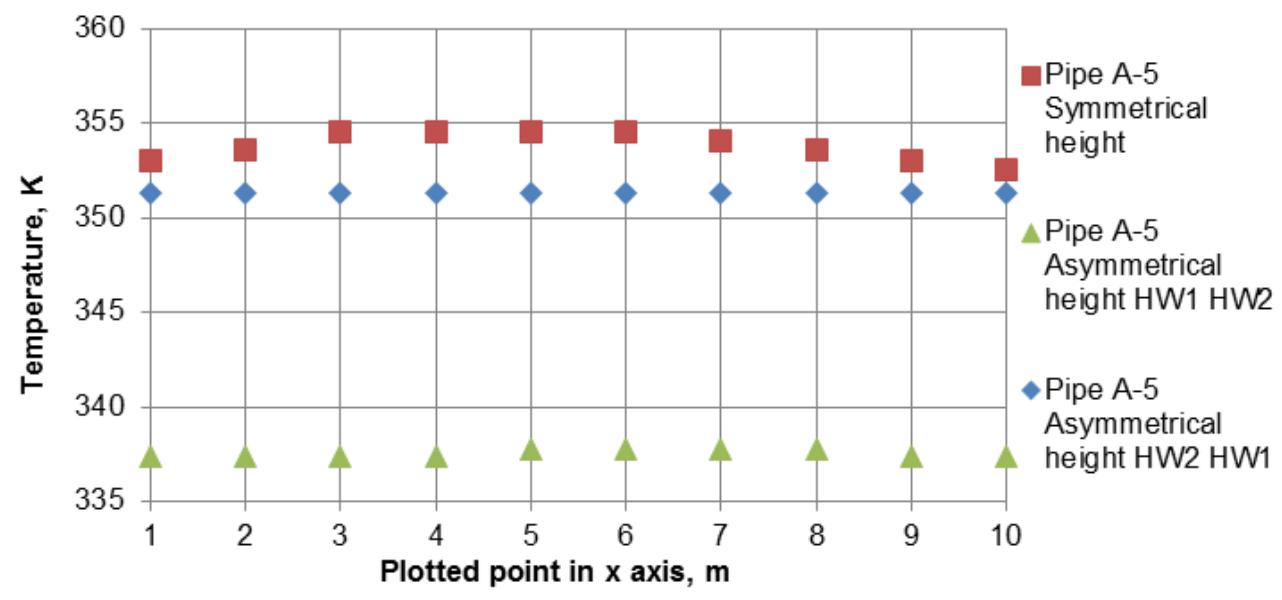

(b)

Pipe B-5

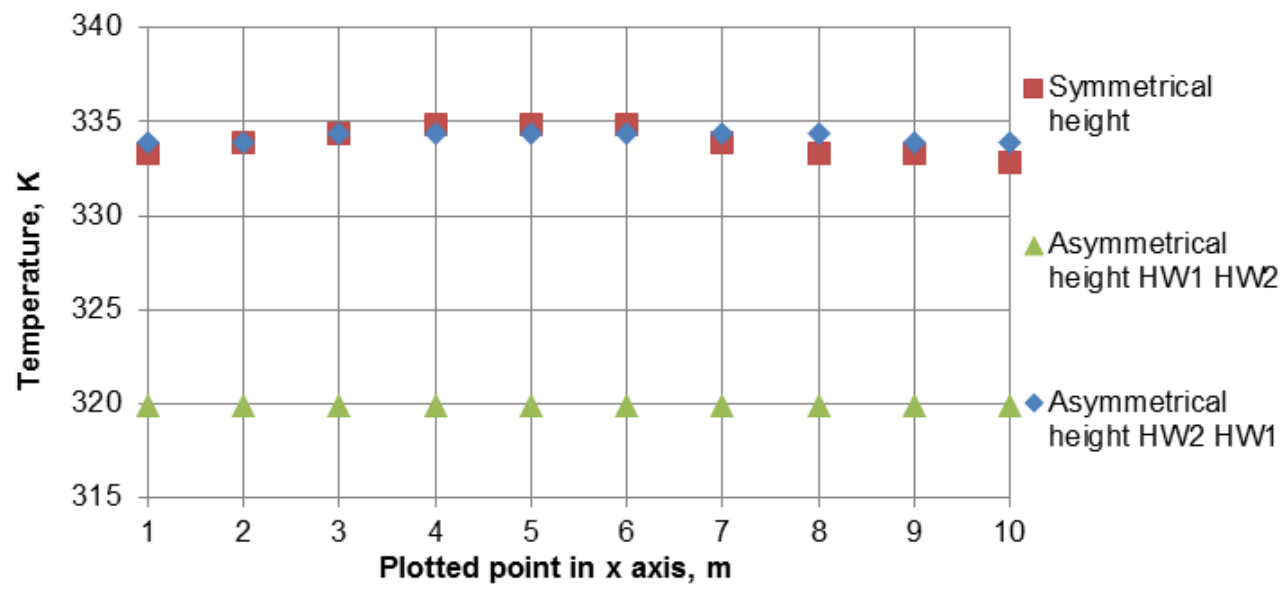

(c)

Figure 11: Surface temperature values plotted on 10 points comparing 
441 Figure 12 compares the potential temperature collection (PTC) in \% based on the temperature 442 difference between the outlet water temperature and the inlet water temperature (Delta T) of the RPSC system. It was observed that in overall, the PTC values during hot summer day were not less than 20.0 $\%$ and not more than $50.0 \%$. At all locations where the comparison was based on the street canyon configuration in Figure 12; it was found that the highest PTC values obtained by symmetrical canyon height were $53.26 \%$ and $4.58 \%$ more than the asymmetrical canyon height Type 1 and the asymmetrical canyon height Type 2 , respectively.

\section{Performance analysis in PTC (\%)}

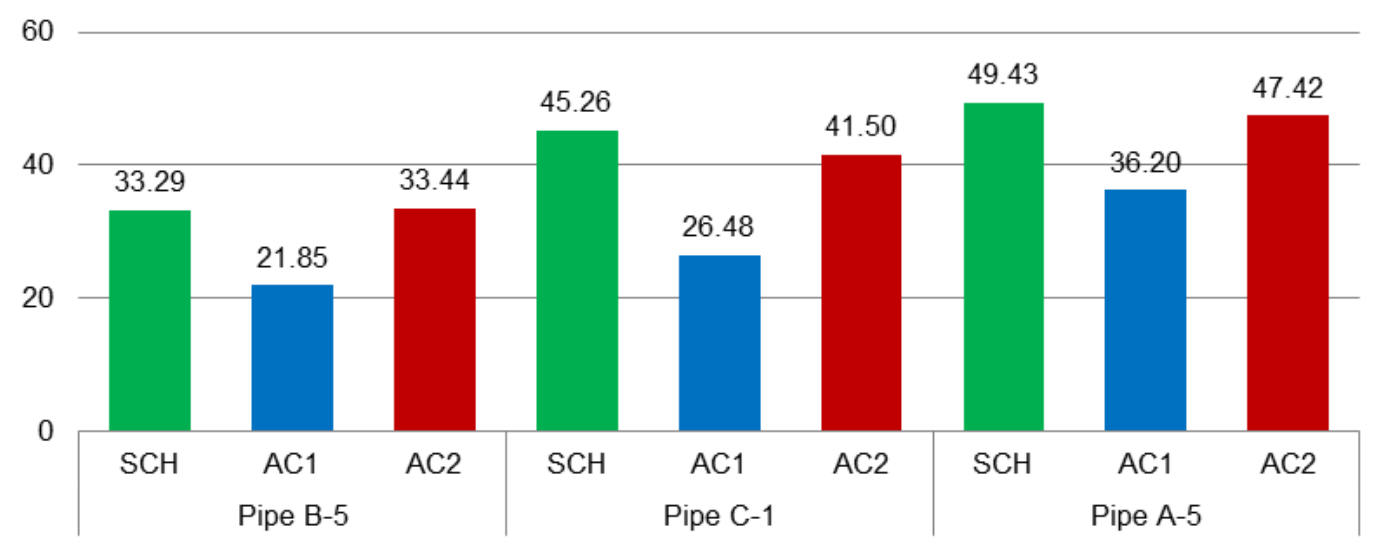

SCH = Symmetrical Canyon Height, AC1 = Asymmetrical Canyon Height Type 1, AC2 = Asymmetrical Canyon Height Type 2

Figure 12: Potential Temperature Collection (PTC) in \%

\subsubsection{Surface temperature reduction (STR) in \%}

Based on Figure 13, it can be observed that surface temperature reduction (STR) for all canyon configurations were not less than $35.0 \%$ and not more than $50.0 \%$. significant difference in values were found when comparing the asymmetrical canyon height Type 1 and the other two canyon settings, which was on average $15.0 \%$ less in the STR performance. Insignificant difference can be found when comparing the symmetrical canyon height and asymmetrical canyon height Type 2, which was on average $1.2 \%$. For the location B-5 where the RPSC pipes B-5 were located, it should be highlighted that both PTC and STR values based on the simulation of asymmetrical canyon height Type 2 have dominated the PTC and STR values based on the simulation of symmetrical canyon height by $0.15 \%$. 


\section{Performance analysis in STR (\%)}

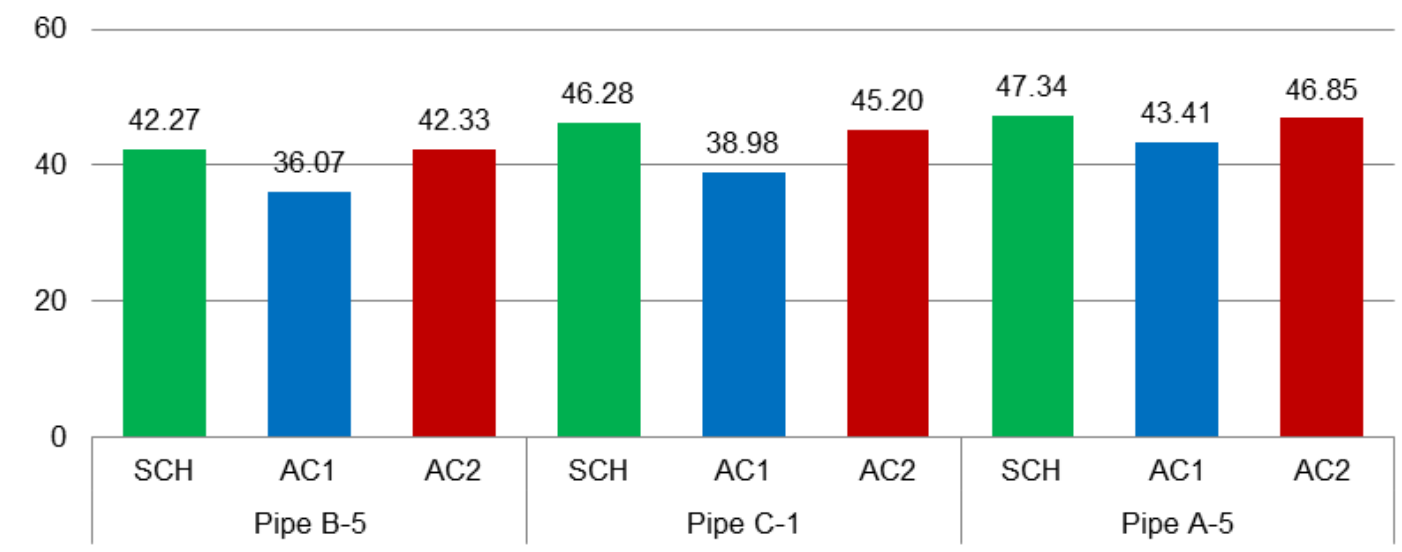

SCH = Symmetrical Canyon Height, AC1 = Asymmetrical Canyon Height Type 1, AC2 = Asymmetrical Canyon Height Type 2

Figure 13: Surface Temperature Reduction (PTC) in \%

\subsection{Conclusions and future work}

This study evaluated the effect of the urban form on canyon road surface and on the performance of the RPSC system which highlighted the modification of height in building rows under three settings: (i) symmetrical canyon height, (ii) asymmetrical canyon height Type 1 - the height of first approaching building row is shorter than the second building row, and (iii) asymmetrical canyon height Type 2 - the height of first approaching building row is taller than the second building row. Several conclusions were made:

(i) Temperature contours of canyon road surface for symmetrical canyon height had shown that the direction of colder to hotter spots was from the canyon openings (right and left) toward the centre of the surface area meanwhile from the simulation of asymmetrical canyon height Type 2, the temperature contour of canyon road surface received almost $60.0 \%$ identical throughout the surface area. During hot summer days, the optimum RPSC embedment within asymmetrical canyon height was found to be the centre location and for the asymmetrical canyon height Type 2, the optimum RPSC embedment was alongside the street canyon.

(ii) Lower temperature was obtained by the canyon road surface of the asymmetrical canyon height Type 1, as compared to the other two canyon configurations, dominated by the swirling air within the street canyon due to the obstruction of the second building row (Building B). 
(iii) A significantly lower average surface temperature (20.14-23.08\%) was obtained at the location C-1, A-5 and B-5 when comparing asymmetrical canyon height Type 1 with the other two canyon settings.

(iv) Significant PTC and STR was obtained by embedding RPSC pipes within the symmetrical canyon height and asymmetrical canyon height Type 2 with the average PTC performance ranging between 30.0-49.0\% and not less than $40.0 \%$ STR.

(v) The PTC and STR of the RPSC pipes within the asymmetrical canyon height Type 1 was approximately $50.0 \%$ lower in terms of the PTC and $15.0 \%$ lower performance in STR behind the other two canyon settings.

A significant variation of the temperature contour between the three canyon settings was observed, and therefore the RPSC embedment with the length of the pipes oriented parallel to width of the street canyon should be further evaluated to find an optimum performance value in PTC and STR. Not only this, a significant impact was found by increasing the building height on the surface temperature condition and the performance of RPSC system. Thus, evaluation of the building configuration during hot summer day(s) by comparing several heights seems promising to be carried out in the future.

\section{Acknowledgement}

This research is supported by Energy 2050 under the Faculty of Engineering, The University of Sheffield, United Kingdom. Special gratitude is also given to Malaysia government agency, Majlis Amanah Rakyat (MARA) for the 4 years' scholarship of Malaysian postgraduate $\mathrm{PhD}$ study.

(1)

.

.
1

2

3


518 [1] R. A. Memon and D. Y. C. Leung, "On the heating environment in street canyon," Environ. Fluid Mech., vol. 11, no. 5, pp. 465-480, 2011.

R. Priyadarsini, W. N. Hien, and C. K. Wai David, "Microclimatic modeling of the urban thermal environment of Singapore to mitigate urban heat island," Sol. Energy, vol. 82, no. 8, pp. 727-745, 2008.

P. a. Mirzaei and F. Haghighat, "A procedure to quantify the impact of mitigation techniques on the urban ventilation," Build. Environ., vol. 47, no. 1, pp. 410-420, 2012. Montazeri, and H. J. P. Timmermans, "CFD simulation and validation of urban microclimate: A case study for Bergpolder Zuid, Rotterdam,” Build. Environ., vol. 83, pp. 79-90, 2015.

G. Levermore and H. Cheung, "A low-order canyon model to estimate the influence of canyon shape on the maximum urban heat island effect," Build. Serv. Eng. Res. Technol., vol. 33, no. 4, pp. 371-385, 2012.

B. Blocken, J. Carmeliet, and T. Stathopoulos, "CFD evaluation of wind speed conditions in passages between parallel buildings-effect of wall-function roughness modifications for the atmospheric boundary layer flow," J. Wind Eng. Ind. Aerodyn., vol. 95, no. 9-11, pp. 941-962, 2007.

[10] J. Allegrini, V. Dorer, and J. Carmeliet, "Coupled CFD, radiation and building energy model for studying heat fluxes in an urban environment with generic building configurations," Sustain. Cities Soc., vol. 19, pp. 385-394, 2015.

S. Bottillo, a. De Lieto Vollaro, G. Galli, and a. Vallati, "Fluid dynamic and heat transfer parameters in an urban canyon," Sol. Energy, vol. 99, pp. 1-10, 2014.

R. A. Memon, D. Y. C. Leung, and C. H. Liu, "Effects of building aspect ratio and wind speed on air temperatures in urban-like street canyons," Build. Environ., vol. 45, no. 1, pp. 176-188, 2010.

J. Allegrini, V. Dorer, and J. Carmeliet, "Analysis of convective heat transfer at building facades in street canyons and its influence on the predictions of space cooling demand in buildings," J. Wind Eng. Ind. Aerodyn., vol. 104-106, pp. 464-473, 2012.

\author{
Sustain. Cities Soc., vol. 19, pp. 385-394, 2015.
}

1] Nazarian and J. Kleissl, "CFD simulation of an idealized urban environment: Thermal effects of geometrical characteristics and surface materials," Urban Clim., vol. 12, pp. 141- 
159, 2015.

549

550

551

552

553

554

555

556

557

558

559

560

561

562

563

564

565

566

567

568

569

570

571

572

573

574

575

576

577

[12] K. Li and Z. Yu, "Comparative and combinative study of urban heat island in Wuhan City with remote sensing and CFD simulation," Sensors, vol. 8, no. 10, pp. 6692-6703, 2008.

[13] J. Allegrini, V. Dorer, T. Defraeye, and J. Carmeliet, "An adaptive temperature wall function for mixed convective flows at exterior surfaces of buildings in street canyons," Build. Environ., vol. 49, no. 1, pp. 55-66, 2012.

[14] J. K. Calautit, B. R. Hughes, and S. S. Shahzad, "CFD and wind tunnel study of the performance of a uni-directional wind catcher with heat transfer devices," Renew. Energy, vol. 83, pp. 85-99, 2015.

[15] J. Allegrini, V. Dorer, and J. Carmeliet, "Influence of the urban microclimate in street canyons on the energy demand for space cooling and heating of buildings," Energy Build., vol. 55, pp. 823-832, Dec. 2012.

[16] Y. Tamura and P. Van Phuc, "Development of CFD and applications: Monologue by a nonCFD-expert," J. Wind Eng. Ind. Aerodyn., vol. 144, pp. 3-13, 2015.

[17] G. Antonioni, S. Burkhart, J. Burman, A. Dejoan, A. Fusco, R. Gaasbeek, T. Gjesdal, A. Jäppinen, K. Riikonen, P. Morra, O. Parmhed, and J. L. Santiago, "Comparison of CFD and operational dispersion models in an urban-like environment," Atmos. Environ., vol. 47, pp. 365-372, 2012.

[18] T. Defraeye, B. Blocken, and J. Carmeliet, "Convective heat transfer coefficients for exterior building surfaces : Existing correlations and CFD modelling," Energy Convers. Manag., vol. 52, no. 1, pp. 512-522, 2011.

[19] J. Franke, A. Hellsten, H. Schlünzen, and B. Carissimo, Best practice guideline for the CFD simulation of flows in the urban environment, vol. 44, no. May. 2007.

[20] S.-A. Tan and T.-F. Fwa, "Influence of pavement materials on the thermal environment of outdoor spaces," Build. Environ., vol. 27, no. 3, pp. 289-295, 1992.

[21] Y. Qin and J. E. Hiller, "Modeling temperature distribution in rigid pavement slabs: Impact of air temperature," Constr. Build. Mater., vol. 25, no. 9, pp. 3753-3761, 2011.

[22] V. Bobes-Jesus, P. Pascual-Muñoz, D. Castro-Fresno, and J. Rodriguez-Hernandez, “Asphalt solar collectors: A literature review," Appl. Energy, vol. 102, pp. 962-970, Feb. 2013.

[23] S. Hasebe, M, Yamikawa, Y and Meiarashi, "Thermoelectric generators using solar thermal 
energy in heated road pavement," ... , 2006. ICT'06. 25th ..., pp. 697-700, 2006.

579

580

581

582

583

584

585

586

587

588

589

590

591

592

593

594

595

596

597

598

599

600

601

602

603

604

605

606

607

608

[24] H. Wang, S. Wu, M. Chen, and Y. Zhang, "Numerical simulation on the thermal response of heat-conducting asphalt pavements," Phys. Scr, vol. 14041, pp. 11-14, 2010.

[25] M. A. AL-SAAD, B. A. JUBRAN, and N. A. ABU-FARIS, "DEVELOPMENT AND TESTING OF CONCRETE SOLAR COLLECTORS,” Int. J. Sol. Energy, vol. 16, no. 1, pp. 27-40, 1994.

[26] P. Pascual-Muñoz, D. Castro-Fresno, P. Serrano-Bravo, and a. Alonso-Estébanez, "Thermal and hydraulic analysis of multilayered asphalt pavements as active solar collectors," Appl. Energy, vol. 111, pp. 324-332, 2013.

[27] M. D'Antoni and O. Saro, "Massive Solar-Thermal Collectors: A critical literature review," Renew. Sustain. Energy Rev., vol. 16, no. 6, pp. 3666-3679, 2012.

[28] R. Borinaga-treviño, P. Pascual-muñoz, D. Castro-fresno, J. José, and D. Coz-díaz, "Study of different grouting materials used in vertical geothermal closed-loop heat exchangers," Appl. Therm. Eng., vol. 50, no. 1, pp. 159-167, 2013.

[29] H. Wang and Z. Chen, "Study of critical free-area ratio during the snow-melting process on pavement using low-temperature heating fluids," Energy Convers. Manag., vol. 50, no. 1, pp. 157-165, 2009.

[30] J. A. Alfaro-ayala, G. Martínez-rodríguez, M. Picón-núñez, A. R. Uribe-ramírez, and A. Gallegos-muñoz, "Numerical study of a low temperature water-in-glass evacuated tube solar collector," Energy Convers. Manag., vol. 94, pp. 472-481, 2015.

[31] F. R. Mazarrón, C. J. Porras-prieto, J. L. García, and R. M. Benavente, "Feasibility of active solar water heating systems with evacuated tube collector at different operational water temperatures," Energy Convers. Manag., vol. 113, pp. 16-26, 2016.

[32] W. Tian, Y. Wang, J. Ren, and L. Zhu, "Effect of urban climate on building integrated photovoltaics performance," Energy Convers. Manag., vol. 48, pp. 1-8, 2007.

[33] D. S. N. M. Nasir, B. R. Hughes, and J. K. Calautit, "A study of the impact of building geometry on the thermal performance of road pavement solar collectors," Energy, vol. 93, pp. 2614-2630, 2015.

[34] D. S. Nasir, B. R. Hughes, and J. K. Calautit, "A CFD analysis of several design parameters of a road pavement solar collector ( RPSC ) for urban application," Appl. Energy, vol. 186, pp. 436-449, 2017. 
[35] B. Blocken, T. Stathopoulos, and J. Carmeliet, "CFD simulation of the atmospheric boundary layer: wall function problems," Atmos. Environ., vol. 41, no. 2, pp. 238-252, 2007.

[36] W. Shaopeng, C. Mingyu, and Z. Jizhe, "Laboratory investigation into thermal response of asphalt pavements as solar collector by application of small-scale slabs," Appl. Therm. Eng., vol. 31, no. 10, pp. 1582-1587, Jul. 2011.

[37] R. Anniballe, S. Bonafoni, and M. Pichierri, "Spatial and temporal trends of the surface and air heat island over Milan using MODIS data," Remote Sens. Environ., vol. 150, pp. 163-171, 2014.

[38] Fluent, “ANSYS Fluent 12.0 user's guide,” Ansys Inc, vol. 15317, no. November, pp. 1-2498, 2009. 